\title{
IMPACT OF QUASI-DC CURRENTS \\ ON THREE-PHASE DISTRIBUTION TRANSFORMER INSTALLATIONS
}

\author{
B.W. McConnell \\ P.R. Barnes \\ Energy Division \\ Oak Ridge National Laboratory' \\ Oak Ridge, Tennessee \\ F.M. Tesche \\ Consultant \\ Dallas, Texas \\ D.A. Schafer \\ Mission Research Corporation \\ Albuquerque, New Mexico
}

June 1992

Research Jointly Sponsored by

Defense Nuclear Agency

Washington, DC 20585

DNA IACRO 90.822

\author{
Department of Energy \\ Office of Energy Management \\ Washington, DC 20585
}

Under Interagency Agreement No. 0046-C156-A 1

Prepared by the

OAK RIDGE NATIONAL LABORATORY

Oak Ridge: Tennessee 37831-6285

Managed by

MARTIN MARIETTA ENERGY SYSTEMS, INC.

for the

U.S. DEPARTMENT OF ENERGY

Under Contract DE-AC05-84OR21400 


\section{TABLE OF CONTENTS}

$\underline{\text { Section }}$ Page

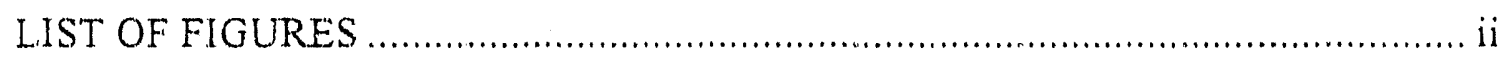

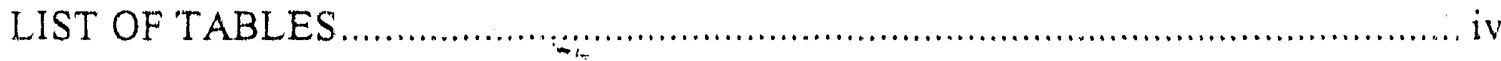

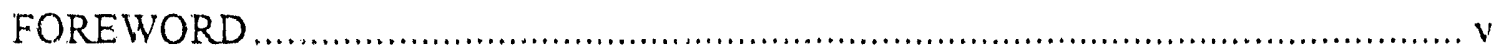

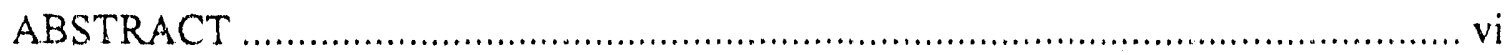

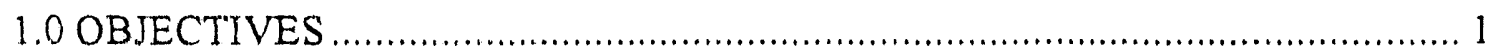

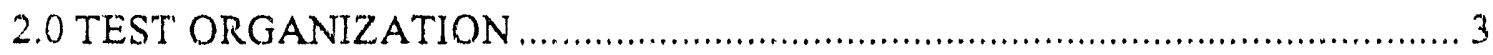

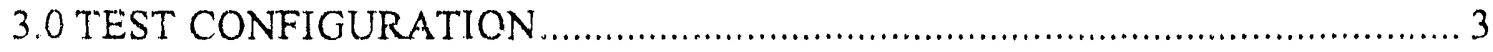

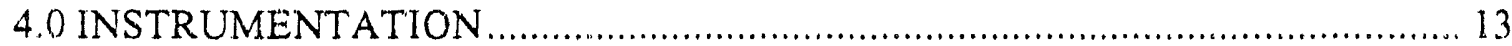

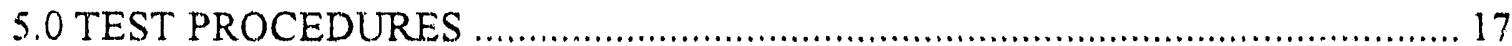

6.0 DATA PROCESSING FOR THE DISTRIBUTION TRANSFORMER TEST ...... 18

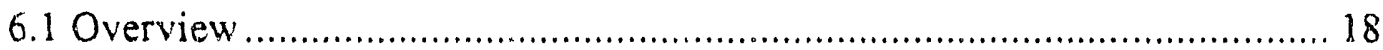

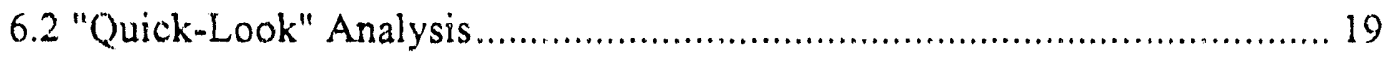

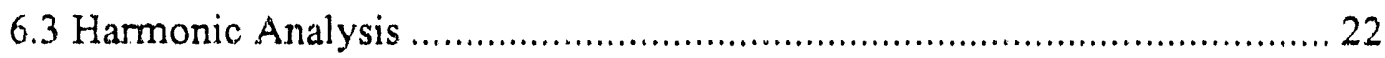

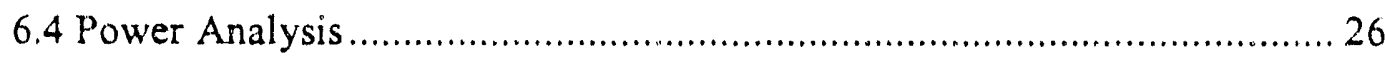

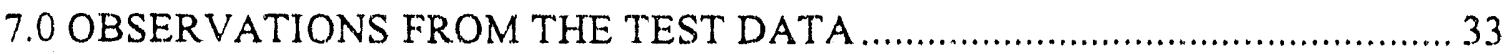

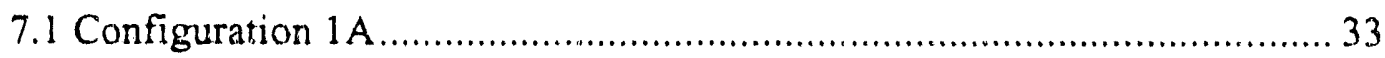

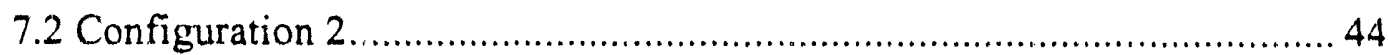

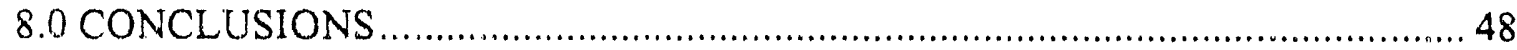

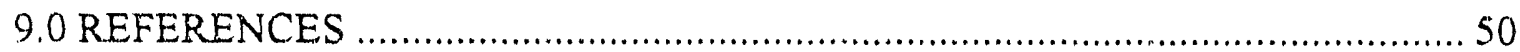




\section{LIST OF FIGURES}

Figure

Figure 1. Commercial 480-V Source Configuration. ......................................... 4

Figure 2. Test Configuration 1A

Figure 3. Test Configuration 1B................................................................. 5

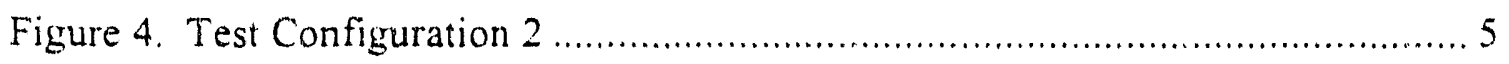

Figure 5. Transformer Model and Test Set-ups ................................................ 7

Figure 6. An Alternate, More Precise Transformer Model........................................ 10

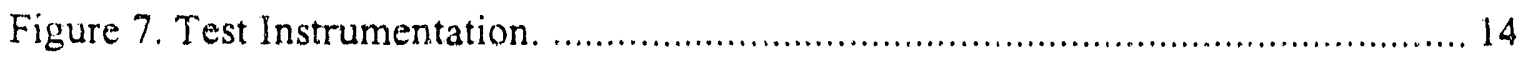

Figure 8. Measured Transfer Impedance $\left(Z_{t}\right)$ for T\&M Research Current Probe. ....... 16

Figure 9. Examples of Measured Transient Currents for Different Dc Levels........... 20

Figure 10. Example of the Envelope Plots for the Preliminary Analysis................... 21

Figure 11. Examples of Computed Spectra for Measured Responses.......................... 23

Figure 12. Plots of the Analytical Current Probe Impedance Function ....................... 25

Figure 13. Corrected Spectrum of Fig. 9b Using the Probe Correction Function of

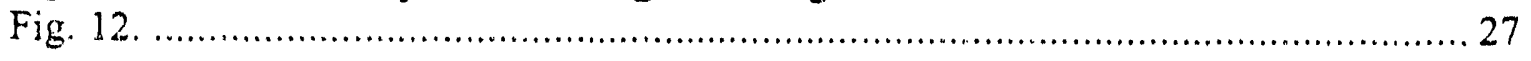

Figure 14. Examples of Principal Harmonic Content for Measured Waveforms. ........ 28

Figure 15. Complex 60-Hz Power Computed for Phase 1 with No Dc Excitation....... 30

Figure 16. Complex Power for Phase 1 Configuration 1A, With 5.5 A DC

Excitation Switched On, Off, and On.

Figure 17. Envelope Plots of the 12.47-kV Phase 1 Current for Configuration $1 \mathrm{~A}$ for Different Levels of Dc Injection Switched On, Off, and On

Figure 18. Envelope Plots of the 12.47-kV Phase 1 Voltage for Configuration $1 \mathrm{~A}$ with Different Levels of Dc Injection Switched On, Off, and On. 35

Figure 19. Envelope Plots for Phases 1 and 2 Currents for Various Levels of Dc Injection Switched On, Off, and On (Phase 3 Not Measured). 


\section{LIST OF FIGURES (Con't)}

Figure

Figure 20. Envelope Plots for the Neutral Currents in the $12.47 \mathrm{kV}$ Line for

Various Levels of De Injection Switched On, Off, and On.

Figure 21. Load Current Envelopes for Configuration 1A with De Switched On, Off, and On.

Figure 22. Harmonic Content vs. Dc Current Level for Phase 1, Configuration 1A... 40

Figure 23. Reactive Power on Phase 1 vs. De Current Injection Level.

Figure 24. System Relaxation Time vs. Dc Current Injection Level for

Configuration $1 \mathrm{~A}$.

Figure 25. Neutral Current in Transformer Secondary (Load) for Configuration 1B with No De Injection. 43

Figure 26. Harmonic Cuntent vs. Dc Current Level for Phase 1 of Configuration 2. . 45

Figure 27. Reactive Power on Phase 1 vs. Dc Current Injection Level. 46 


\section{LIST OF TABLES}

Iable

Table 1. Transformer and Load Bank Characteristics ........................................6

Table 2. Measured Transformer Circuit Parameters...............................................

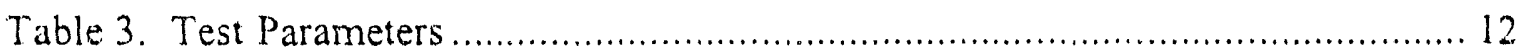

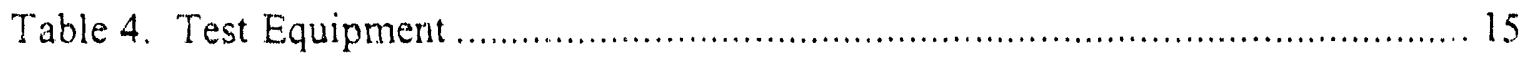




\section{FOREWORD}

This work was sponsored by the Defense Nuclear Agency (DNA) under Interagency Agreement No. 0046-C156-A.1 with the Department of Energy and was conducted under DOE Contract No. DE-AC05-840R21400 with Martin Marietta Energy Systems, manager of Oak Ridge National Laboratory, in cooperation with Mission Research Corporation and the Public Service Company of New Mexico. Assistance in the testing was provided by two subcontractors to Martin Marietta Energy Systems: ABB Power Systems, Inc., and Dr. Frederick M. Tesche, Consultant. 


\begin{abstract}
This report summarizes a series of tests designed to determine the response of quasi-dc currents on three-phase power distribution transformers for electric power systems. In general, if the dc injection is limited to the primary side of a step-down transformer, significant harmonic distortion is noted and an increase in the reactive power demand results. For dc injection on the secondary (load) side of the step-down transformer, the harmonic content at the secondary side is quite high and saturation occurs with a relatively low level of do injection; however, the reactive power demand is significantly lower. These tests produced no apparent damage to the transformers. Transformer damage is dependent on the duration of the dc excitation, the level of the excitation, and on the thermal characteristics of the transformer.

The transformer response time is found to be much shorter than seen in power transformei tests at lower dc injection levels. This shorter response time suggests that the response time is strongly dependent on the injected current levels, and that higher levels of dc injection for shorter durations could produce very high reactive power demands and harmonic distortion within a few tenths of a second.

The added reactive power load could result in the blowing of fuses on the primary side of the transformer for even moderate de injection levels, and neutral currents are quite large under even low-level de injection. This "smoking neutral" results in high-level harmonic injection into equipment via the neutral and in possible equipment failure.
\end{abstract}




\section{IMPACT OF QUASI-DC CURRENTS \\ ON THREE-PHASE DISTRIBUTION TRANSFORMER INSTALLATIONS}

\subsection{OBJECTIVES}

It is a well-established fact that geomagnetic storms influence electrical power transmission and distribution systems [1-3]. Previous cases of such storms in the northern latitudes have resulted in occasional power disruptions and, in some cases, damage to transformers [4]. These effects are caused by a time variation of the earth's magnetic field creating an induced electric field (E-field) along the surface of the earth. This E-field acts as a voltage source along long power transmission or distribution lines, and if such lines are connected to the earth at both ends, a quasi-static current can flow. This current can cause unwanted saturation in the magnetic cores of transformers in the power system, which in turn produces harmonic distortion and transformer heating. This harmonic distortion and heating can lead to system upset (shutdown) and possibly transformer burn-out.

A high-altitude nuclear explosion is also known to affect the magnetosphere, producing late-time variations of the earth's magnetic field for several hundreds of seconds. Known as the magnetohydrodynamic electromagnetic pulse (MHD-EMP), or $E_{3}$, this magnetic field disruption is of particular concern to electrical power systems. Its effects are similar to those of geomagnetic storms. Although the MHD-EMP-induced currents can be significantly larger in magnitude, they last for a shorter period of time than do those from a geomagnetic storm. The effects of the MHD-EMP environment compound the adverse effects of the early-time high altitude EMP (HEMP) environment [5], posing a potentially serious threat to the electrical power systern.

In order to increase the understanding of the effects of the MHD-EMP environment on electrical power sy'stems, several investigations have been conducted. An initial study [6] has developed the framework for understanding the MHD-EMP interaction with power systems, and outlines a methodology for assessing the system behavior in this environment. A subsequent report [7] continues with studies of MHD-EMP coupling to realistic transmission and distribution lines, using more up-to-date environments.

The present report documents an experimental program designed to increase the understanding of the behavior of distribution-class power transformers subjected to quasi-dc current excitation. Given the knowledge of the MHD-EMP-induced current flowing in a lorg 
power line, and the given transformer response characteristics determined in this program, more accurate assessments of the behavior of the overall power system to EMP can be made.

The experimental program was conducted in June of 1990 at the Mission Research Corporation in Albuquerque, NM, and involved constructing a mock-up of a simple 3-phase $12.47-\mathrm{kV}$ distribution system using two distribution-class power transformers and a dummy 3-phase load bank. This system was fed by local commercial power. Measurements on this system were made with the following specific objectives in mind:

1. To determine the effect of quasi-dc currents on the operation of three-phase transformer banks.

2. To measure voltage and current harmonics within the system and the loads.

3. To assess the importance of the quasi-de current duration.

4. To determine the change in reactive power demand as a function of quasi-dc currents.

5. To determine if low-level quasi-de currents and the distorted ac current can cause primary fuses to blow.

Objectives 1, 2, and 4 were met taking data directly from these measurements, while objectives 3 and 5 were met by interpreting the data. 


\subsection{TEST ORGANIZATION}

For this experimental program, the Oak Ridge National Laboratory (ORNL) was the lead organization. ORNL responsiblities included performing the functions of project coordination, test plan development, pretest and posttest analysis, and writing the final report. Assisting ORNL was Dr. F. M. Tesche, a private consultant. During the measurement phase of the program, support was provided by Aesa Brown Boveri (ABB) Power Systems, Inc. Mission Research Corporation (MRC) in Albuquerque provided the test site, and all equipment and personnel associated with the data measurement, storage, viewing, and conversion. MRC also provided the dc current injection source and the 480-V 3-phase commercial power hook-up. The Public Service Company of New Mexico provided the $208-\mathrm{V} / 12.47-\mathrm{kV}, \quad 75-\mathrm{kVA} \mathrm{Y}-\mathrm{Y}$ and the $480-\mathrm{V} / 12.47-\mathrm{kV}, 300-\mathrm{kVA}, \mathrm{Y}-\mathrm{Y}$ 3-phase transformers for the test. In addition, MRC obtained a $12.47-\mathrm{kV} / 208 \mathrm{~V}, \Delta-\mathrm{Y}, 75-\mathrm{kVA} 3-$ phase transformer under a purchase order from $\mathrm{ABB}$.

\subsection{TEST CONFIGURATION}

For this test, a mock-up of a power distribution system was made in the MRC test bay. An existing 480-V 3-phase commercial power service was available for the primary energy source. This energy source had the configuration shown in Figure 1, where 90-A slow-blow fuses served as primary protection. The fuse box and service disconnect switch were connected to a $30 \mathrm{ft} 1 / 0$ cable leading to the test area, where a 200-A 3-phase contactor was used to energize and deenergize the transformers being tested.

Three different transformer configurations were used in this test. These are shown in Figures 2, 3, and 4. The first configuration, denoted as $1 \mathrm{~A}$, involved the $480-\mathrm{V} / 12.47-\mathrm{kV}$, $300-k V A, Y-Y$ transformer, shown as $\mathrm{Tl}$, and the $12.47-\mathrm{kV} / 208-\mathrm{V}, 75 \cdot \mathrm{kVA}, \mathrm{Y}-\mathrm{Y}$ transformer, shown as T2. The neutrals of the secondary $(12.47 \mathrm{kV}$ side) of $\mathrm{T} 1$ and the primary (12.47 kV side) of T2 were connected to the dc injection source, which simulated the MHD-EMP excitation of a long distribution line terminated by grounded $Y-Y$ transformers at each end. Three resistive dummy loads comprised a nominal $60-\mathrm{kW}$ load for transformer $\mathrm{T} 2$. This load was estimated to be about $80 \%$ of the design load for this transformer. The total 60 ' $\mathrm{z}$ current in each phase as supplied by the $480 \mathrm{-V}$ source was estimated to be 80 to $88 \mathrm{~A}$. T able 1 summarizes the transformer and load bank characteristics. 


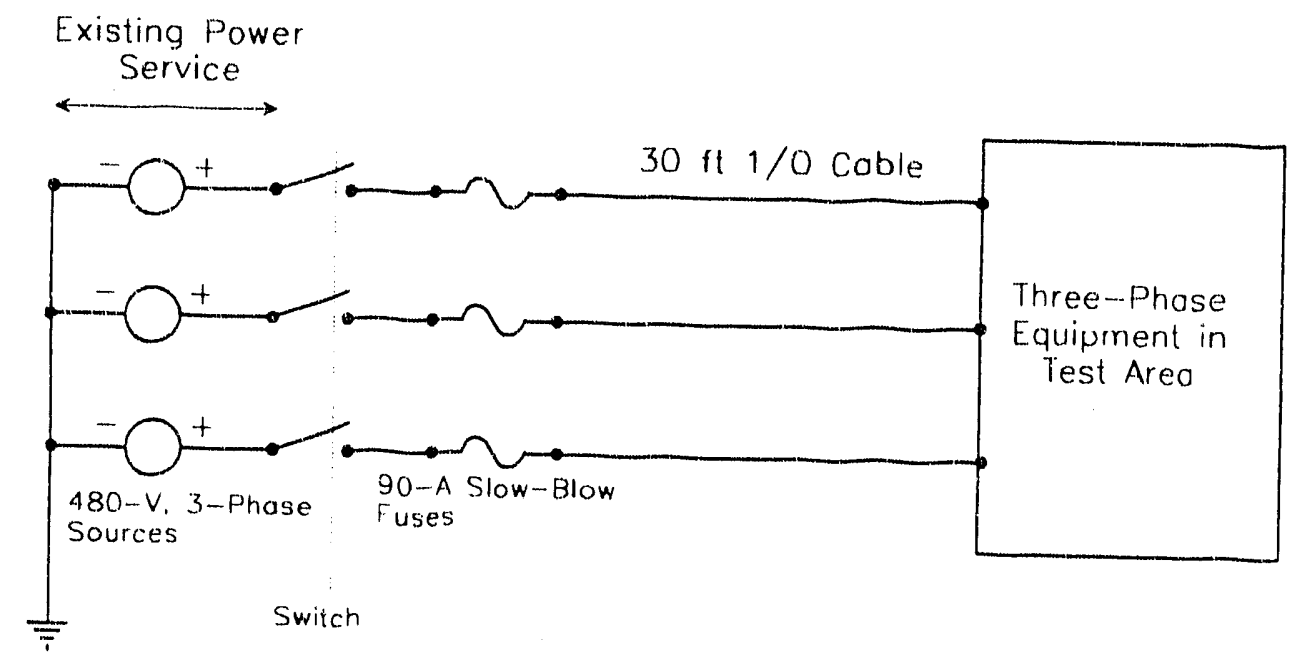

Figure 1. Commercial 480-V Source Configuration.

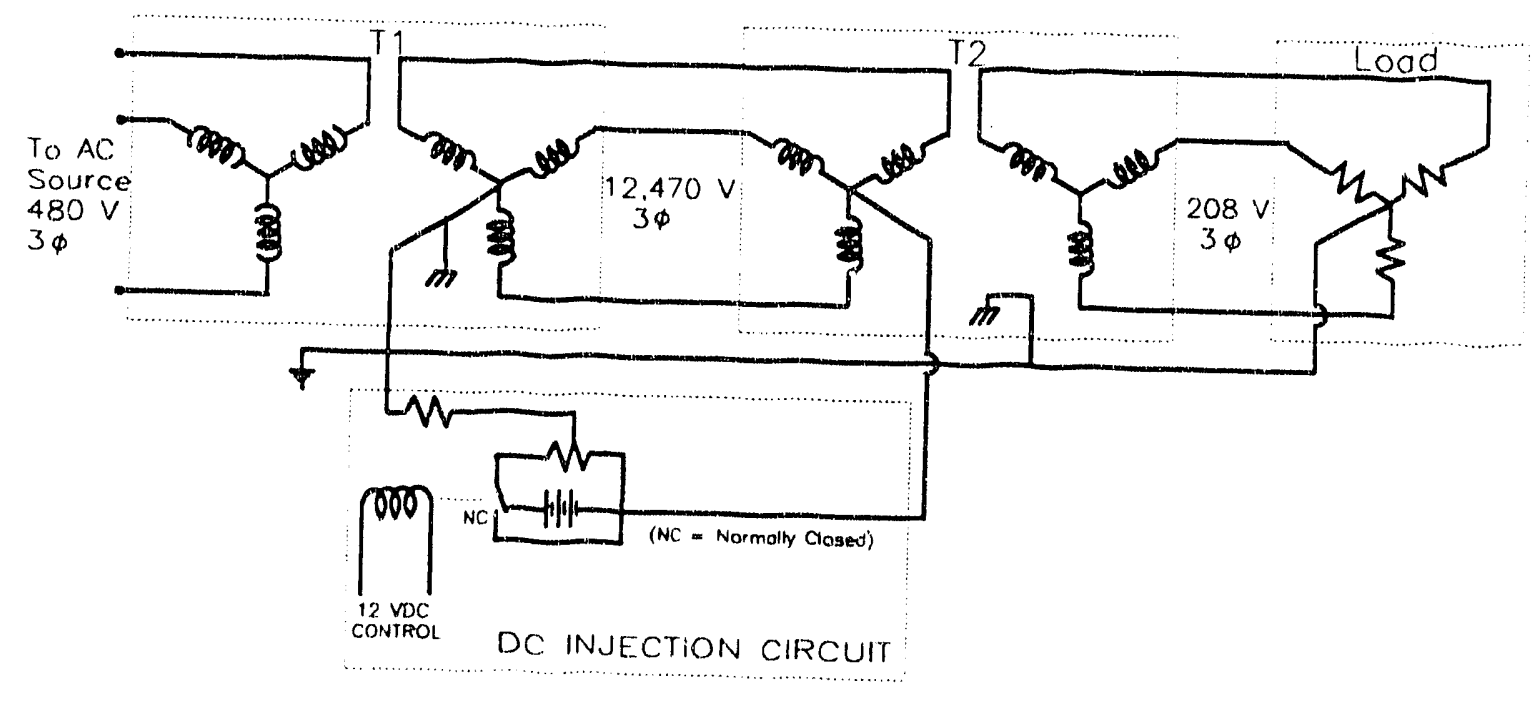

Figure 2. Test Configuration 1A. 


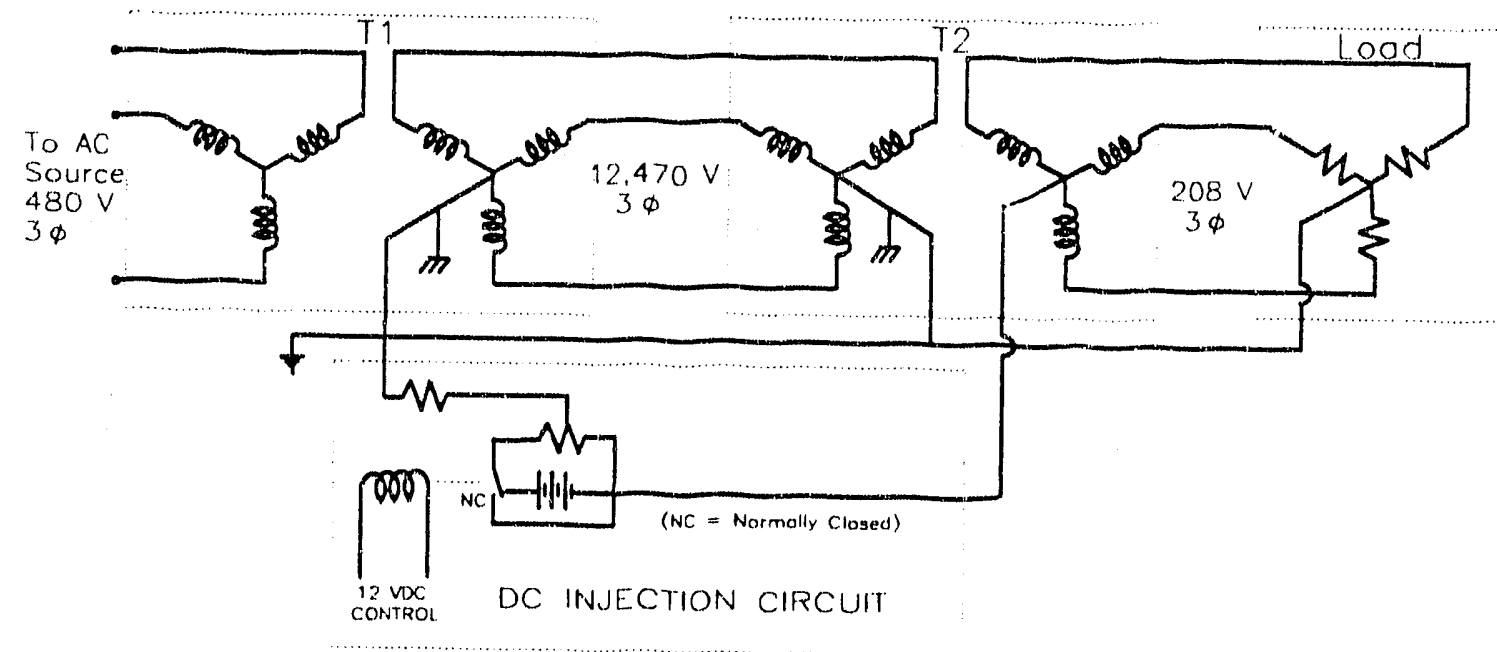

Figure 3. Test Configuration 1B.

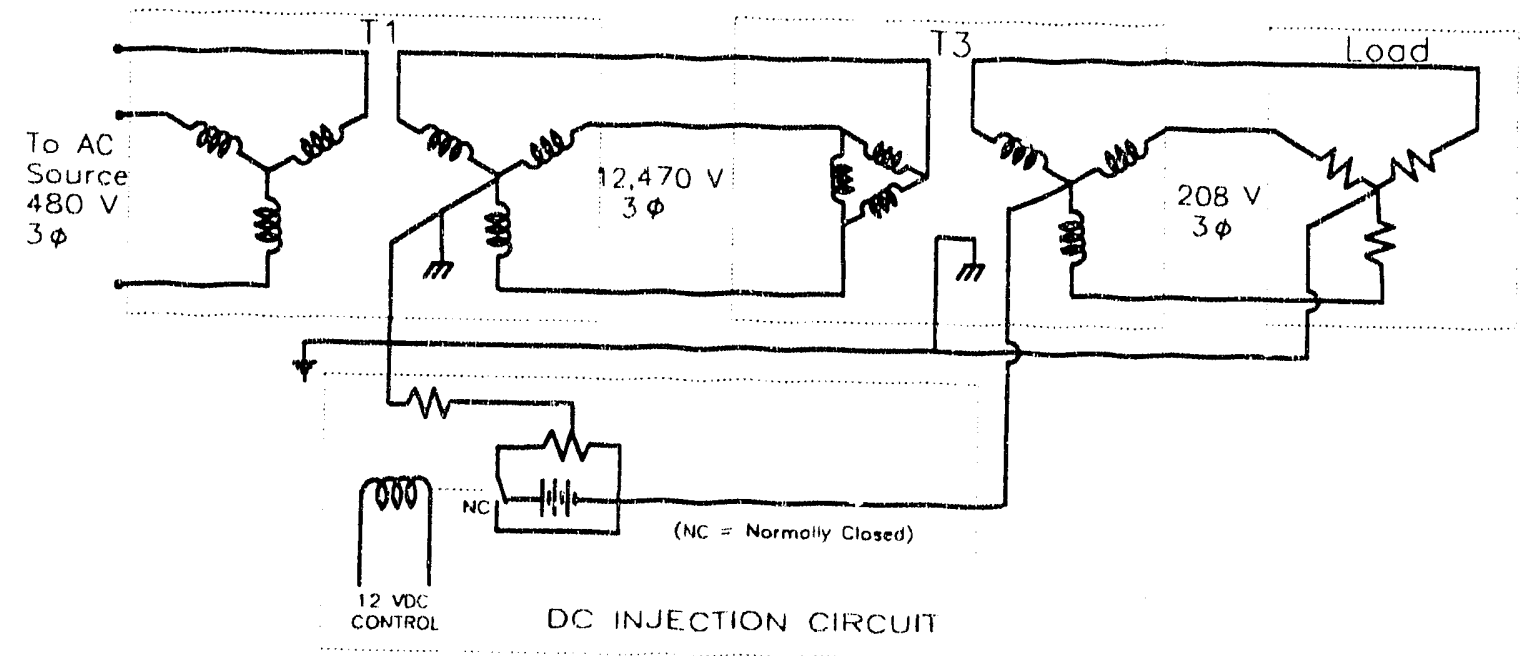

Figure 4. Test Configuration 2. 
Takle 1.

Transformer and Load Bank Characteristics

\begin{tabular}{|c|c|c|}
\hline Equipment & Model No. & Description \\
\hline T1 GE Transformer & K860313T72AA & $300-k V A 12.47-k V / 480-V Y \cdot Y 3 \phi$ \\
\hline T2 GE Transformer & M31859TTFPA & 75-kVA $12.47-k V / 208-V Y-Y 3 \phi$ \\
\hline T3 Weiver Transformer & 23490 & 75-kVA $12.47-\mathrm{kV} / 208-\mathrm{V} \Delta-\mathrm{Y} 3 \phi$ \\
\hline Load Banks & & $\begin{array}{l}\text { Three } 55 \text {-gailon drums with water } \\
\text { heater elements in parallel. De } \\
\text { resistance: Phase } 1-0.68 \Omega \text {, Phase } 2 \\
-0.70 \Omega \text {, Phase } 3-0.72 \Omega \text {. }\end{array}$ \\
\hline
\end{tabular}

The second system configuration (1B) shown in Figure 3 , irvolved the same transformers as configuration $1 \mathrm{~A}$, but the quasi-dc excitation was provided in the secondary (208. V side) load circuit of transformer T2. The last test configuration, denoted by configuration 2 in rigure 4 , shows the $12.47-\mathrm{kV} / 208 \mathrm{~V}, \Delta-\mathrm{Y}, 75-\mathrm{kVA}$ transformer as $\mathrm{T} 3$, with the quasi-dc again being induced in the load side of $T 3$. In each of these configurations, the primary side of transformer $T 1$ is considered to be the $480 \mathrm{~V}$ side, and the secondary-side is the $12.47 \mathrm{kV}$ side. For transformers T2 and T3, the primary-side is the $12.47 \mathrm{kV}$ section, and the secondary is the $208 \mathrm{~V}$ side.

For the purpose of possible future modeling efforts, we wanted to obtain a suitable electrical model for the transformers used in this test. Figure 5a illustrates one possible circuit model for a single phase of the three phases of a general transformer [8]. The shunt resistance and inductance elements $R_{c}$ and $L_{c}$ represent the core loss and the core magnetizing induc:ance, and the series elements $R_{t}$ and $L_{l}$ represent the winding resistance and the leakage inductance of the transformer windings. Connected to these elements is an ideal transformer having a turns ratio of 1:a. In these models, we assume that the primary is the low-voltage side of the transformer and the secondary is the high-voltage winding. Thus, the turns ratio "a" is greater than unity.

At the conclusion of the testing, measurement were made for determining the appropriate parameters for the three transformers used in the experiment. These tests 
involved a short-circuit test to determine $R_{t}$ ard $I_{\text {w }}$, as well as an open-circuit test for $R_{c}$ and $L_{c}$. These tests and their rationale are discussed in detail in ref.[8]. The genera: test setup for these measurements is shown in Figures $5 b$ and $5 c$, along with the relations for determining the pararneters $G, B, R$, and $X$. These parameters are related to the element values in Figure sa by $G=1 / R_{c}, B=-1 / \omega L_{c}, R=R_{t}$, and $X=\omega L$

For the open-circuit tests, the low-voltage winding was excited with the high-voltage winding open, as shown in Figure 5b. Since only limited current could be supplied by the $480-\mathrm{V} 3$-phase $(277 \mathrm{~V} /$ phase) commercial power hook-up at the test facility, the short-circuit tests for each of the transformers were conducted by driving the high-voltage winding with the low-voltage winding shorted. This was done to insure that the transformers were being excited with normal current levels. This change in the test procedure requires a slight modification of the expressions used for computing the $\mathrm{R}$ and $\mathrm{X}$ elements in Figure $5 \mathrm{c}$ : the turns ratio " $\mathrm{a}$ " in the expressions in Figure $5 \mathrm{~b}$ should be taken to be unity. This modification is needed because the measurement is performed on the sarne winding on the transformer where the $R$ and $X$ elements are located. Tab! 2 presents the measured circuit values for the three transformers.
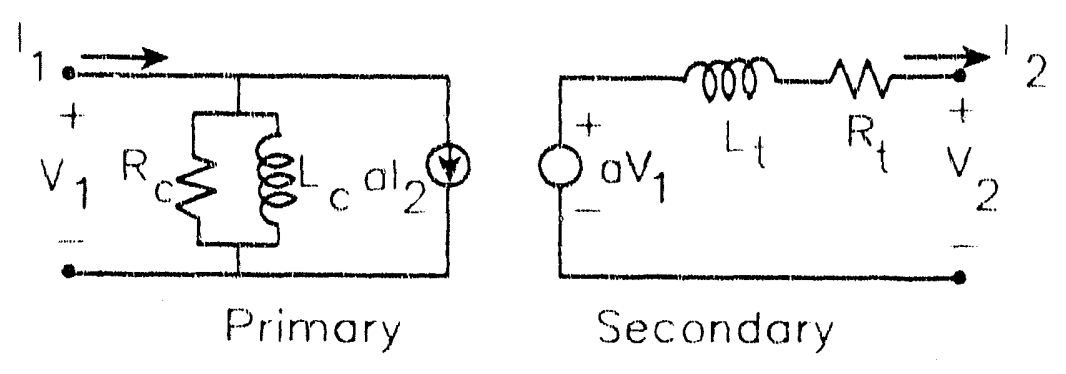

a. A Simplified Transformer Model.

Figure 5. Transformer Model and Test Set-ups. 


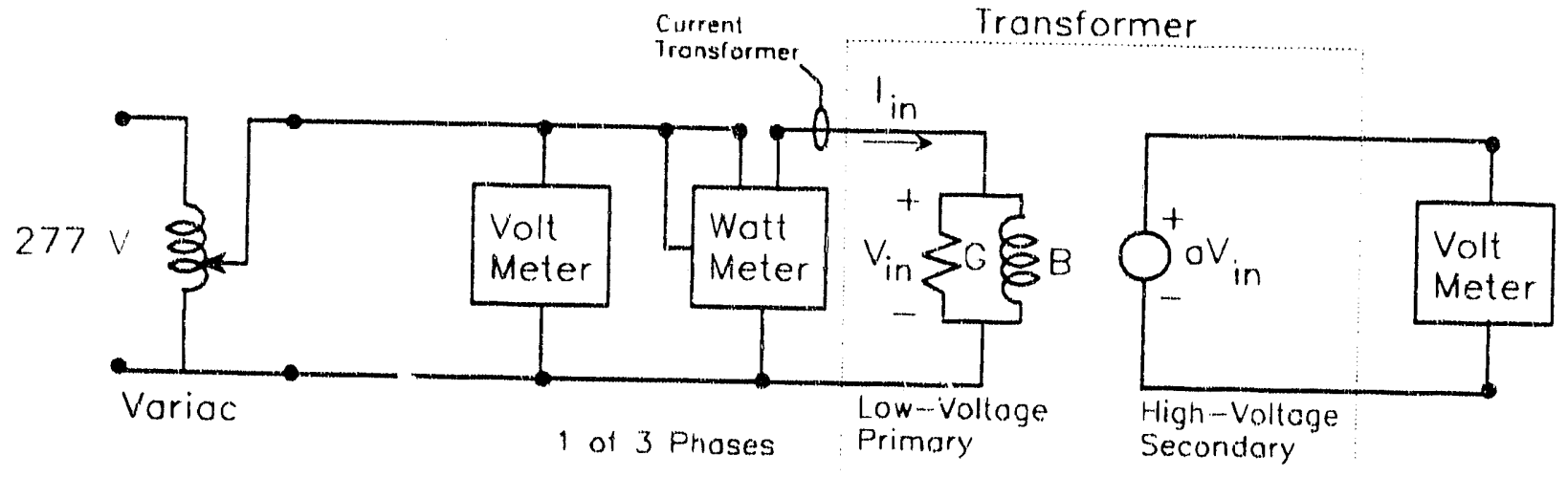

Open Circuit Test: $\quad G=\frac{\text { Input Power }}{V_{\text {in }}^{2}} \quad B=\sqrt{\left(I_{\text {in }} / V_{\text {in }}\right)^{2}-G^{2}}$

b. Test Configuration for Core Loss Measurements (Open Circuit)

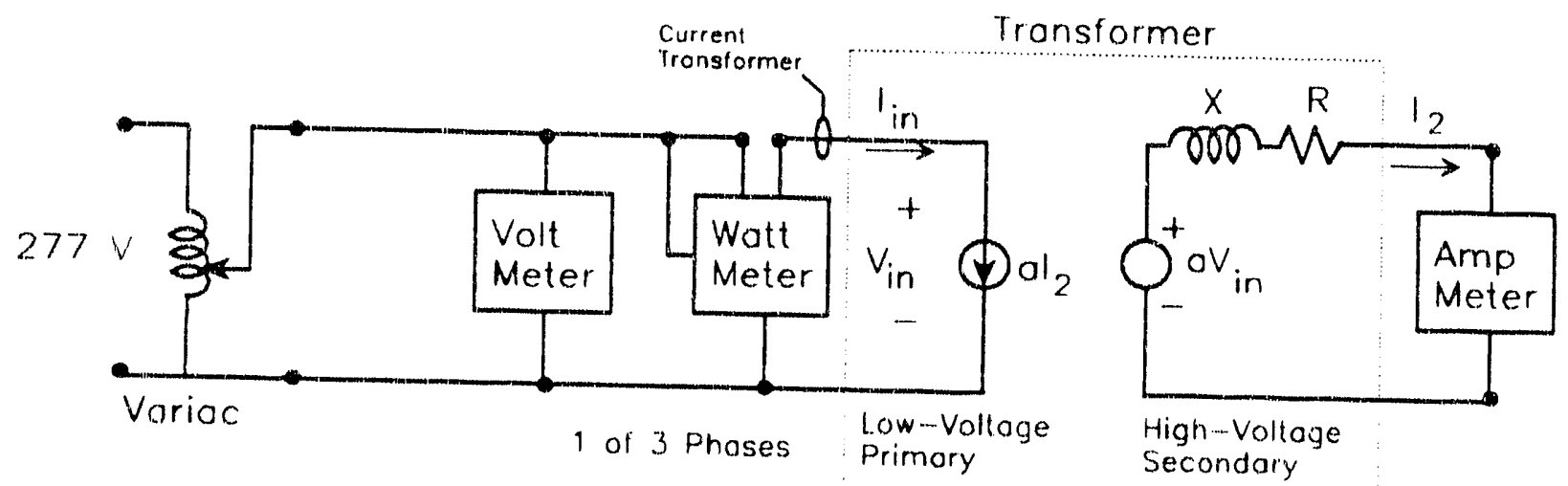

Short Circuit Test: $R=\frac{a^{2} \text { input Power }}{1_{\text {in }}^{2}} \quad x=\sqrt{\left(a^{2} V_{\text {in }} / I_{i n}\right)^{2}-R^{2}}$

c. Test Configuration for Copper Loss Measurements (Short Circuit)

Figure 5. Transformer Model and Test Set-ups (Concluded). 
Table 2.

Measured Transformer Circuit Parameters

300-kVA Y-Y Transformer T1 $(a=26)$

\begin{tabular}{|c|c|c|c|c|}
\hline Phase & $\mathbf{R}_{\mathbf{c}}(\boldsymbol{\Omega})$ & $\mathbf{L}_{\mathbf{c}}(\mathbf{h})$ & $\mathbf{R}_{\mathbf{t}}(\boldsymbol{\Omega})$ & $\mathbf{L}_{\mathbf{t}}(\mathbf{m h})$ \\
\hline 1 & 157 & 0.40 & 3.6 & 26.3 \\
\hline 2 & 273 & 0.58 & 3.7 & 25.0 \\
\hline 3 & 317 & 0.37 & 3.9 & 25.4 \\
\hline
\end{tabular}

75-kVA Y-Y Transformer T2 $(\mathrm{a}=60)$

\begin{tabular}{|c|c|c|c|c|}
\hline Phase & $\mathbf{R}_{\mathbf{c}}(\boldsymbol{\Omega})$ & $\mathbf{L}_{\mathbf{c}}(\mathbf{h})$ & $\mathbf{R}_{\mathbf{t}}(\mathbf{\Omega})$ & $\mathbf{L}_{\mathbf{t}}(\mathbf{m h})$ \\
\hline 1 & 53 & 0.09 & 20.9 & 51.5 \\
\hline 2 & 136 & 0.14 & 20.4 & 52.3 \\
\hline 3 & 337 & 0.09 & 21.5 & 51.5 \\
\hline
\end{tabular}

75-kVA Y- Transformer T3 $(\mathrm{a}=60)$

\begin{tabular}{|c|c|c|c|c|}
\hline Phase & $\mathbf{R}_{\mathbf{c}}(\boldsymbol{\Omega})$ & $\mathbf{L}_{\mathbf{c}}(\mathbf{h})$ & $\mathbf{R}_{\mathbf{t}}(\boldsymbol{\Omega})$ & $\mathbf{L}_{\mathbf{t}}(\mathbf{m h})$ \\
\hline 1 & 145 & 0.70 & 22.4 & 84.5 \\
\hline 2 & 145 & 0.81 & 19.9 & 102.5 \\
\hline 3 & 156 & 0.87 & 23.4 & 90.7 \\
\hline
\end{tabular}


As discussed in ref.[8], alternate transformer representations are possible. Figure 6 illustrates one possible model in which the elements $R_{t}$ and $L_{t}$ are split, with part being located in the primary circuit and part being put in the secondary circuit. Of course, the fraction being put in the primary circuit must be scaled by a factor $1 / \mathrm{a}^{2}$.

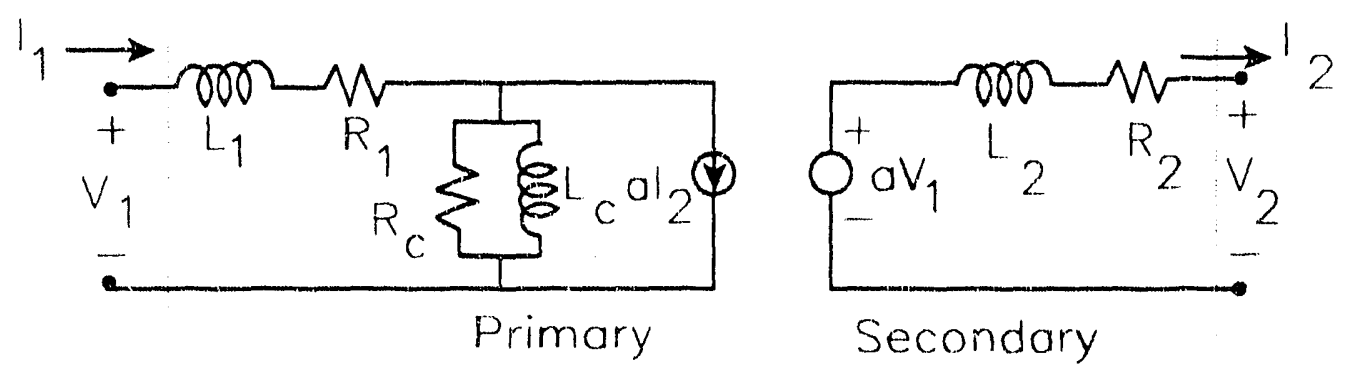

Figure 6. An Alternate, More Precisu Transformer Model.

The equivalent circuit model in Figure $5 \mathrm{a}$ and the values in Table 2 are based on the assumption of a linear operation of the transformor. The nonlinear core saturation characteristics of the transformers were not measured; consequently, the above transformer model is not sufficient for a complete nonlinear characterization of the devices. As will be noted in Section 7.0, these transformers were frequently driven into nonlinear operating regions by the dc neutral excitation currents. It is possible that with the data presented in this report, along with a reasonable assumption of the transformer core behavior, a suitable nonlinear operating model could $b$ r. developed. Such a model, however, is beyond the scope of the present effort, and is not considered further in this report.

For each of the transformer configurations depicted in Figures 2 to 4 , the dc injection circuitry is shown in the lower portion of the circuit. With the switch position such that the battery is in the circuit, a dc current is injected into the neutral circuit. A measurement of the approximate ac neutral current with the battery in the circuit, but without do injection, can be obtained with the switch in the normally closed position. For dc injection, the switch is moved to the normally open position. 
The overall measurement program was divided into 22 different tests, which are summarized in Table 3. This table shows the test date, the transformer configuration, and the injected $\mathrm{dc}$ current levels $\left(\mathrm{I}_{\mathrm{dc}}\right)$, as well as the data file identification scheme used for archiving the measured data. In each test, measurements of both voltage and current were made at locations to be discussed in detail below. As indicated by the footnote in Table 3 , the symbol $x$ in the file identifier string represents either $l$ or $V$, depending on the type of measurement made. The $y y$ and $z z$ symbols in the file identifier represent the individual test numbers, 01 through 12. 
Table 3.

Test Parameters

\begin{tabular}{|c|c|c|c|c|c|}
\hline $\begin{array}{l}\text { Test } \\
\text { No. }\end{array}$ & File $\mathrm{ID}^{*}$ & Date & $\begin{array}{c}I_{\mathrm{dc}} \\
\text { (Amps) }\end{array}$ & Config. & Comments \\
\hline 0 & $1 \mathrm{~A} 000 \mathrm{x} 13.0 \mathrm{yy}$ & $6 / 13 / 90$ & 0 & $1 \mathrm{~A}$ & $\begin{array}{c}\text { Base Case for config. } 1 \mathrm{~A} \\
26 \mathrm{sec} \text { duration }\end{array}$ \\
\hline 1 & $1 \mathrm{AD} 06 \mathrm{x} 13.0 \mathrm{yy}$ & $6 / 13 / 90$ & 0.006 & $1 \mathrm{~A}$ & $26 \mathrm{sec}$ duration \\
\hline 2 & 1AD10x13.0yy & $6 / 13 / 90$ & 0.1 & $\overline{1 \mathrm{~A}}$ & 26 sec duration \\
\hline 3 & $1 \mathrm{AD} 60 \times 13.0 y \mathrm{y}$ & $6 / 13 / 90$ & 0.6 & $1 \mathrm{~A}$ & $\ldots$ \\
\hline 4 & 1A1D0x13.0yy & $6 / 13 / 90$ & 1.0 & $1 \mathrm{~A}$ & $\ldots$ \\
\hline 5 & 1A1D5x13.0yy & $6 / 13 / 90$ & 1.5 & $1 \mathrm{~A}$ & $\ldots$ \\
\hline 6 & $1 \mathrm{~B} 10 \mathrm{Dx} 13.0 \mathrm{yy}$ & $6 / 13 / 90$ & 10 & $1 \mathrm{~B}$ & $\ldots$ \\
\hline 7 & $1 \mathrm{~B} 25 \mathrm{Dx} 13.0 \mathrm{yy}$ & $6 / 13 / 90$ & 25 & $1 \mathrm{~B}$ & $\ldots$ \\
\hline 8 & $2 \mathrm{~A} 25 \mathrm{Dx} 14.0 \mathrm{yy}$ & $6 / 14 / 90$ & 25 & $1 \mathrm{~B}$ & $\mathrm{~T} 2$ ungrounded $\mathrm{Y}^{* *}$ \\
\hline 9 & $1 \mathrm{~A} 3 \mathrm{D} 0 \mathrm{x} 14.0 \mathrm{yy}$ & $6 / 14 / 90$ & 3.0 & $1 \mathrm{~A}$ & $\ldots$ \\
\hline 10 & 1A4D5xi4.0yy & $6 / 14 / 90$ & 4.5 & $1 \mathrm{~A}$ & $\ldots$ \\
\hline 11 & $1 \mathrm{~A} 5 \mathrm{D} 5 \mathrm{x} 14.0 \mathrm{yy}$ & $6 / 14 / 90$ & 5.5 & $1 \mathrm{~A}$ & $\ldots$ \\
\hline 12 & 1A000x14.Pyy & $6 / 14 / 90$ & 0 & $1 \mathrm{~A}$ & $\begin{array}{l}\text { Only six channels, } \\
\text { primary only }\end{array}$ \\
\hline 13 & 1A5D5x14.Pyy & $6 / 14 / 90$ & 5.5 & $1 \mathrm{~A}$ & $\begin{array}{l}\text { Only six channels, } \\
\text { primary only }\end{array}$ \\
\hline 14 & 2B000x14.oyy & $6 / 14 / 90$ & 0 & 2 & $\begin{array}{l}\text { Incorrect channel } 8 \text { offset } \\
\text { channel } 4 \text { CT out }\end{array}$ \\
\hline 15 & 2B5D0x14.0yy & $6 / 14 / 90$ & 5.0 & 2 & $\begin{array}{c}\text { Incorrect channel } 8 \text { offset } \\
\text { channel } 4 \mathrm{CT} \text { out }\end{array}$ \\
\hline 16 & 2B10Dx14.0yy & $6 / 14 / 90$ & 10 & 2 & $\begin{array}{l}\text { Incorrect channel } 8 \text { offset } \\
\text { channel } 4 \text { CT out }\end{array}$ \\
\hline 17 & 2B30Dx14.0yy & $6 / 14 / 90$ & 30 & 2 & $\begin{array}{c}\text { Incorrect channel } 8 \text { offset } \\
\text { channel } 4 \text { CT out }\end{array}$ \\
\hline 18 & $2 \mathrm{~B} 20 \mathrm{Dx} 14.0 \mathrm{yy}$ & $6 / 14 / 90$ & 20 & 2 & $\begin{array}{l}\text { Incorrect channel } 8 \text { offset } \\
\text { channel } 4 \text { CT out }\end{array}$ \\
\hline 19 & $2 \mathrm{~B} 57 \mathrm{D} \times 14.0 \mathrm{yy}$ & $6 / 14 / 90$ & 57 & 2 & $\begin{array}{c}\text { Incorrect channel } 8 \text { offset } \\
\text { channel } 4 \text { CT out }\end{array}$ \\
\hline 21 & 2B57Fx14.0yy & $6 / 14 / 90$ & 57 & 2 & $I_{d c}-$ on, off, on \\
\hline 22 & 2B57Fx15.0yy & $6 / 15 / 90$ & 57 & 2 & $I_{d c}-$ on, off, on \\
\hline
\end{tabular}

* Unless noted, all tests were of 15 seconds duration, all 12 channels (Fig. 7) of data were taken, and the test sequence was as follows: ac power on, data recorder on, dc injection on (23 seconds), dc injection off ( $2-3$ seconds), dc injection on (8-10 seconds), dc injection off, data recorder off, ac power off. $\mathrm{x}=\mathrm{I}$ or $\mathrm{V}, \mathrm{yy}=01 \quad 12, \mathrm{zz}=01 \quad 06$.

** Configuration is essentially that of Configuration $1 \mathrm{~B}$ with the primary ground of transformer T2 opened. 


\subsection{INSTRUMENTATION}

The instrumentation configuration for these tests is shown in Figure 7, and a list of the equipment used is presented in Table 4. The main part of the data acquisition process involved 12 simultaneous voltage and current measurements using the Astromed 95000 digital strip chart recorder. The line-neutral voltages on the high-voltage lines at terminals $\mathrm{A}, \mathrm{B}$, and $\mathrm{C}$ of transformer T2 were measured on channels 1,3 , and 5 of the recorder, respectively. The phase currents in lines $A$ and $B$ were measured in channels 2 and 4 with the neutral current being monitored in channel 6 . The phase current in line $C$ was not measured because of insufficient data channels. On the load (secondary) side of T2, load current measurements at $\mathrm{A}, \mathrm{B}$, and $\mathrm{C}$ were made on channels 8,10 , and 12 , and line-neutral voltage measuremerts were made on channels 7,9 , and 11 .

Different types of current and voltage probes were used for these measurements, as indicated in Figure 7. These probes all need a calibration, or "correction," factor to relate their measured output responses to the physical voltage or current quantity being measured. These factors are listed in Table 4.

For most of these probes, the probe correction factors are practically independent of frequency; consequently, a frequency-independent probe correction factor is used. The two T\&M Research current probes used on the $12.47-\mathrm{kV}$ line section for channels 2 and 4 , however, were found to have a response that varied appreciably at frequencies below $100 \mathrm{~Hz}$. Figure 8 shows the measured transfer impedance magnitude of these probes. This quantity is defined as the induced voltage across the probe, $V_{p}$, when measured by a voltmeter with a 50- $\Omega$ input impedance, $Z_{t}$, created by a current of $I_{0}$ amps, and is expressed as $Z_{1}=\left|V_{p} / I_{0}\right|_{Z_{1}=50 \Omega}$. The curve in Figure 8 indicates that the lower $3-d B$ point for these probes is approximately at $70 \mathrm{~Hz}$. Thus, for these probes to be used accurately at $60 \mathrm{~Hz}$, a correction for this frequency fall-off must be used. This problem is discussed in more detail later in the report. Note that at frequencies over about $200 \mathrm{~Hz}$, the probe transfer impedance is a constant of about $0.45 \Omega$. 


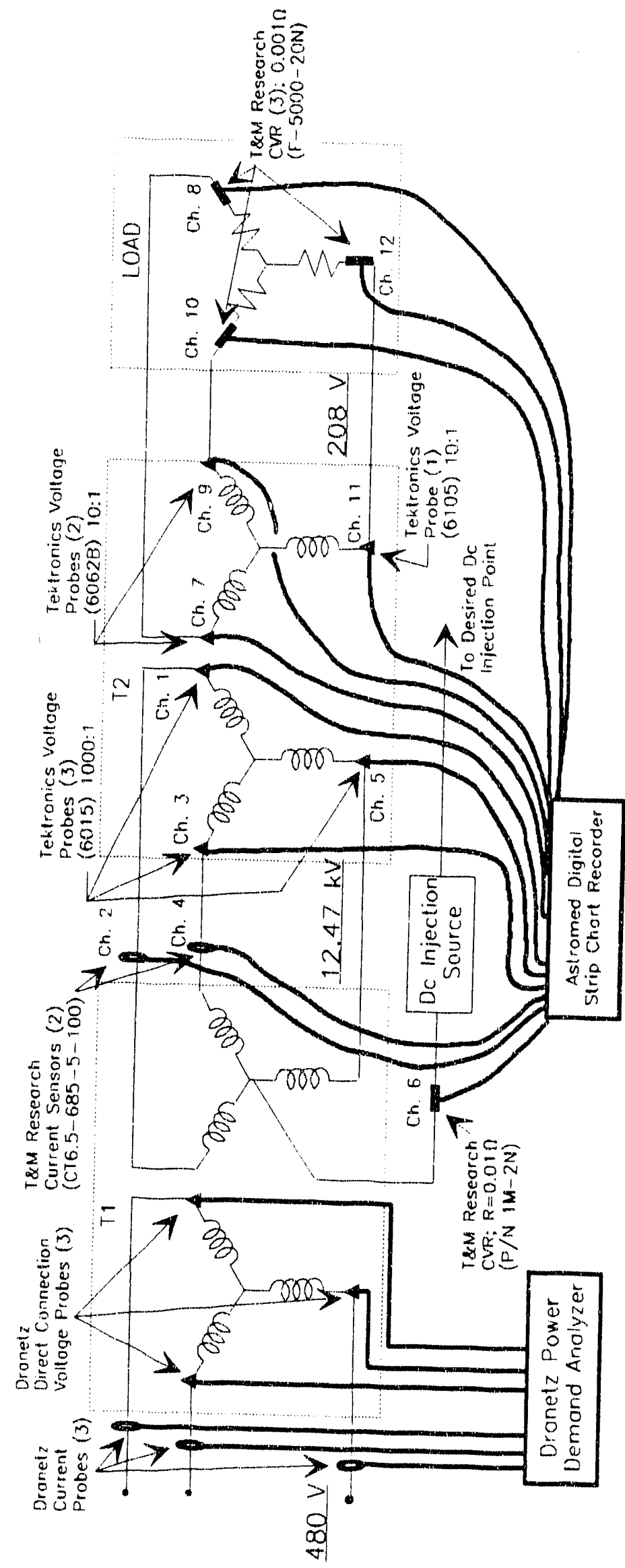

壱 
Table 4.

Test Equipment

\begin{tabular}{|c|c|c|c|}
\hline Equipment & Model No & $\begin{array}{c}\text { Astromed } \\
\text { Measurement } \\
\text { Channels }\end{array}$ & Correction Factor \\
\hline $\begin{array}{c}\text { Dranetz Power Demand } \\
\text { Analyzer }\end{array}$ & 808 & - & $\mathrm{N} / \mathrm{A}$ \\
\hline Dranetz Current Probe & 2013 & - & $\begin{array}{l}\text { Times } 3 \text { accounted for by } \\
\text { Power Demand Analyzer }\end{array}$ \\
\hline $\begin{array}{l}\text { Tektronics Voltage } \\
\text { Probe }\end{array}$ & 6015 & $1,3,5$ & Times 1000 \\
\hline $\begin{array}{c}\text { T\&M Research Current } \\
\text { Viewing Resistor } \\
\text { (CVR) }\end{array}$ & $1 \mathrm{M}-2 \mathrm{~N}$ & 6 & Times 100 \\
\hline $\begin{array}{l}\text { T\&M Research Current } \\
\text { Viewing Resistor } \\
\text { (CVR) }\end{array}$ & F-5000-20N & $8,10,12$ & Times 1000 \\
\hline $\begin{array}{c}\text { T\&M Research Current } \\
\text { Sensor }\end{array}$ & $\begin{array}{l}\text { CT6.5-685- } \\
\quad 5-100\end{array}$ & 2,4 & $\begin{array}{l}\text { Times } 1000 \text { with } R=0.1 \Omega \\
\text { Times } 2000 \text { with } R=0.05 \Omega \\
\text { Times } 2 \text { with } R=50 \Omega \\
\text { (Frequency correction } \\
\text { needed for } 50 \Omega \text { termination) }\end{array}$ \\
\hline $\begin{array}{c}\text { Tektronics Voltage } \\
\text { Probe }\end{array}$ & $6062 B$ & 7,9 & Times 10 \\
\hline $\begin{array}{c}\text { Tektronics Voltage } \\
\text { Probe }\end{array}$ & 6105 & 11 & Times 10 \\
\hline $\begin{array}{l}\text { Astromed } 12 \text { Channel } \\
\text { Digital Strip Chart } \\
\text { Recorder with Deep } \\
\text { Mernory }\end{array}$ & 95000 & - & N/A \\
\hline
\end{tabular}




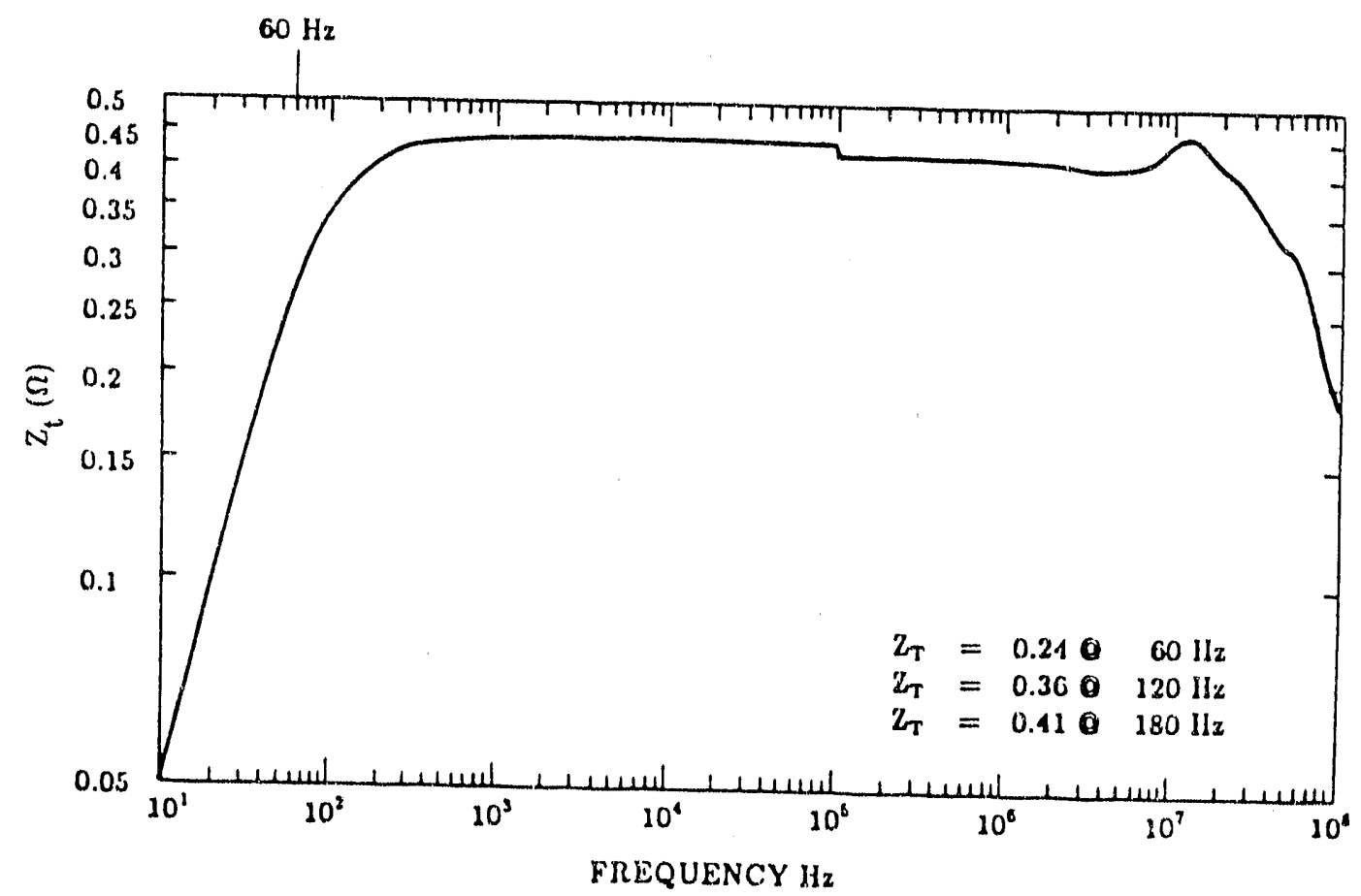

Figure 8. Measured Transfer Impedance $\left(Z_{\downarrow}\right)$ for T\&M Research Current Probe.

The same probes were used occasionally to monitor the input current to the test setup, but in this case, optional low-resistance terminators on the probes were used. While this reduces the sensitivity of the probe (i.e., lowers the transfer impedance), it extends the lower 3-dB point well below $60 \mathrm{~Hz}$. Thus, the frequency-independent scalars for these probes, which are supplied in the data records, are sufficient for the probe calibration factors in this case.

For each test, the input voltage, current, and power were monitored by the Dranetz Power Demand Analyzer, which provided readings of these quantities on a data tape. These quantities served as a check of the overall operation of the system, and provided an additional means of correcting the $\mathrm{V}$ and I measurements on the high-voltage portion of the lines to insure that a power balance is achieved. As will be discussed later, these measurements provide a way of insuring that the probe corrections are done properly. 


\subsection{TEST PROCEDURES}

For each of the transformer configurations shown in Figures 2 through 4 , the tests indicated in Table 3 were conducted. Once the transformers had been connected in the proper manner, the rheostat in the de circuit was adjusted, with no ac excitation on the transformers, to provide the desired dc neutral current level. The battery switch was then placed in the normally-closed (NC) position so no dc excitation of the transformer neutral was present, and the transformars were energized with the commercial $480-\mathrm{V}$ power. The ac neutral current was measured for the case of no dc excitation. After this was complete, the battery was switched into the circuit by energizing the $12 \mathrm{~V}$ control relay. The complete set of voltage and current measurements was made for a fix :d period of time $(13$ seconds for most measurements).

Since the time requircd to reach a steady state response after the power was switched on was found to be significantly less than this measurement time, the 15 second measurement time was more than adequate for this test. Furthermore, in most of the tests, it was possible to disconnect and then reenergize the dc circuit, thereby providing a clear view of the transient relaxation time of the response.

While damage to the transformer was permissible during this test program, the duration of the dc current injection was sufficiently short to preclude such damage, even in the most severe case of current injection. Consequently, no damage to the transformers or loads was noted, aside from the blowing of several fuses on the power feed line to the test setup. This occurred for the initial in-rush current of the energizing transformers, but not for the dc current injection. 


\subsection{DATA PROCESSING FOR THE DISTRIBUTION TRANSFORMER TEST}

\subsection{Overview}

As indicated in Section 4, the voltage and current data from this test program were measured on a 12-channel Astromed MT-9500 transient digitizer. The digitizer pro-ided a plot of the time histories of each of the measured results for a short period of time at the beginning of each measurement, as well as a binary output stream of data which was captured onto a PC disk. As indicated in Table 3, data were acquired for 26 seconds for the first three transformer configurations tested (1A000, 1AD06 and 1AD10). The raw data from the digitizer was contained in 32 packets of binary data, each containing 4096 data samples. This gave a total of 131,072 individual data points, with a resulting raw data file size of 266 KBytes for each of the 12 measurements for these configurations. The data acquisition for the remaining 19 test configurations lasted for 13 seconds; consequently, the raw data file size was $133 \mathrm{KBytes}$ each. For all cases, the resulting time interval between data points was $\mathrm{t}=$ 0.2 milliseconds, or $1.2 \%$ of the $60-\mathrm{Hz}$ period. From this series of tests, 252 separate transient waveforms were measured.

A data translation program was provided by MRC [9] to read each of the raw binary files and convert them to ASCIJ files of ordered time and response data pairs. The resulting sizes of the ASCII data files were 3.54 MBytes for the data taken over the $26 \mathrm{sec}$ time period and 1.8 MBytes for the $13 \mathrm{sec}$ data. This resulted in approximately 538 MBytes of ASCII data for this test.

The first step in the analysis procedure for this test was to perform a "quick-look" (overview) of the measured data. This was done to see if there was any evidence of transformer saturation for the different levels of dc injection. This processing was done for all of the data records. After this preliminary processing was completed and the results analyzed, a more detailed spectral analysis of the data was undertaken. This analysis resulted in plots of the time variations of the $60-\mathrm{Hz}$ components of the measured responses along with the next 5 higher harmonics. A final analysis was conducted to determine the time variations of the real and imaginary components of the $60-\mathrm{Hz}$ power flowing along the distribution line. This is important in considering possible increased reactive power demand on the generation facilities, because of the MHD-EMP excitation of transformers.

Because of the large amount of data acquired in this test and the fact that the processing was done on an IBM PC-class machine, care was used to develop these data 
processing routines in such a way that they would not take an exorbitant amount of processing time or use more disk or memory space than absolutely required. In the following sections, each of these analyses is discussed in more detail, with examples of the processed data being shown.

\section{2 "QUICK-LOOK" ANALYSIS}

Using the MRC-provided data conversion program, a separate routine was writien to read the raw binary data files, convert them into ASCII, and generate a plot file showing the envelope of the measured voltage or current responses. For this quick-look analysis, only the appropriate scalar (frequency independent) measurement probe transfer functions were used. These parameters were imbedded in the binary data file and were used to obtain the measured responses in engineering units (i.e., in volts and amps). The requirement for an implementation of frequency-dependent probe corrections is discussed in the following section on harmonics. Because of the large stoiage requirements for retaining the converted ASCII data, these data files were discarded once they were plotted.

As an example of results from this phase of the analysis, Figure 9 illustrates typical output data for measured currents on channel 2 (the high-voltage side) and channel 8 (the low-voltage side) of the first transformer. These are the actual transient waveforms, shown over a limited time window, for the case of no dc injection into the transformer (Fig. 9a, for Configuration 1A000) and the case of $5.5 \mathrm{~A}$ injection (Fig.9b for Configuration 1A5D5). Part a of the figure is for no dc current injection, and exhibits a reasonably clean $60-\mathrm{Hz}$ sinusoidal waveform. Part $b$ on the other hand, illustrates a highly perturbed waveform arising from the saturation of the transformer cores due to the dc current injection. The secondary current for no de injections is shown in part $c$. Note that some distortion is present on the peaks of the normal $60-\mathrm{Hz}$ sinusoidal waveform. This may indicate that the transformer was near magnetic saturation under normal operating conditions. The waveform in part $d$ is clearly more distorted than the corresponding primary waveform in part $b$ with 5.5 A dc injection. The transformer shows no tendency to "block" these lower-order harmonics and may have enhanced them. 

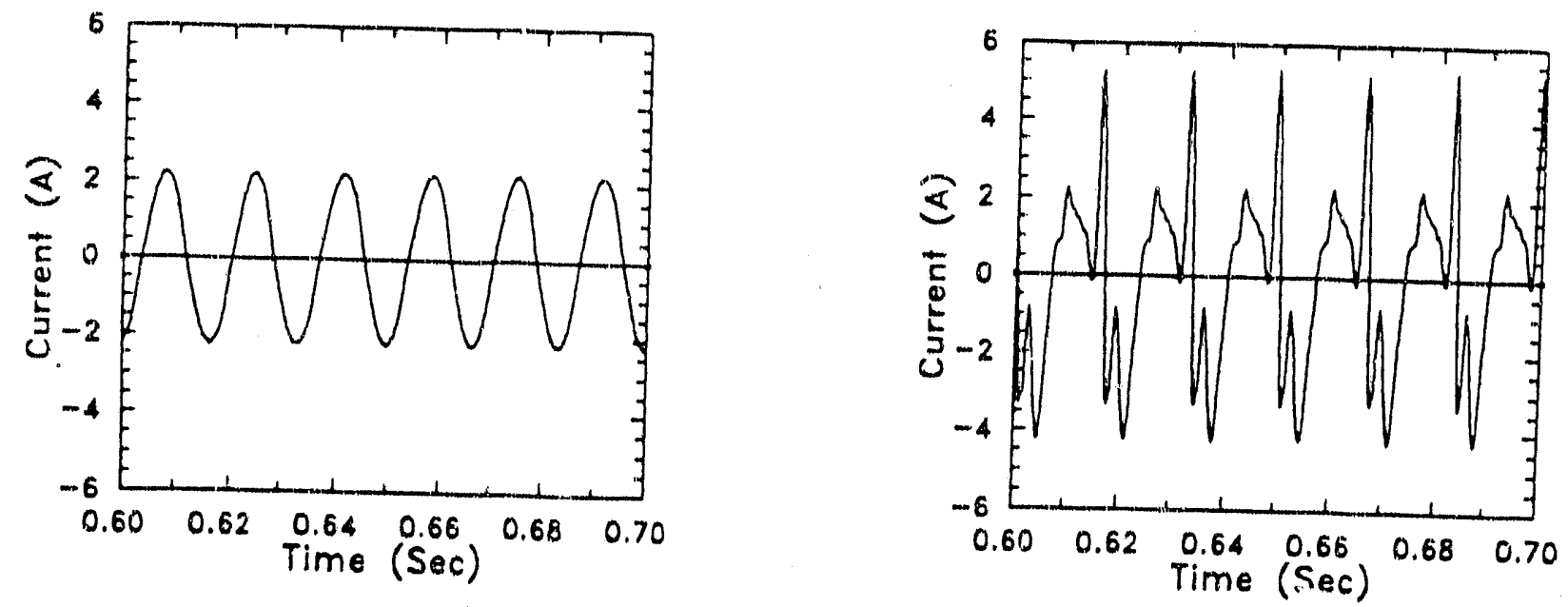

a. Primary Current (Channel 2) for 0.0 A Dc

b. Primery Current (Channel 2) for 5.5 A Dc
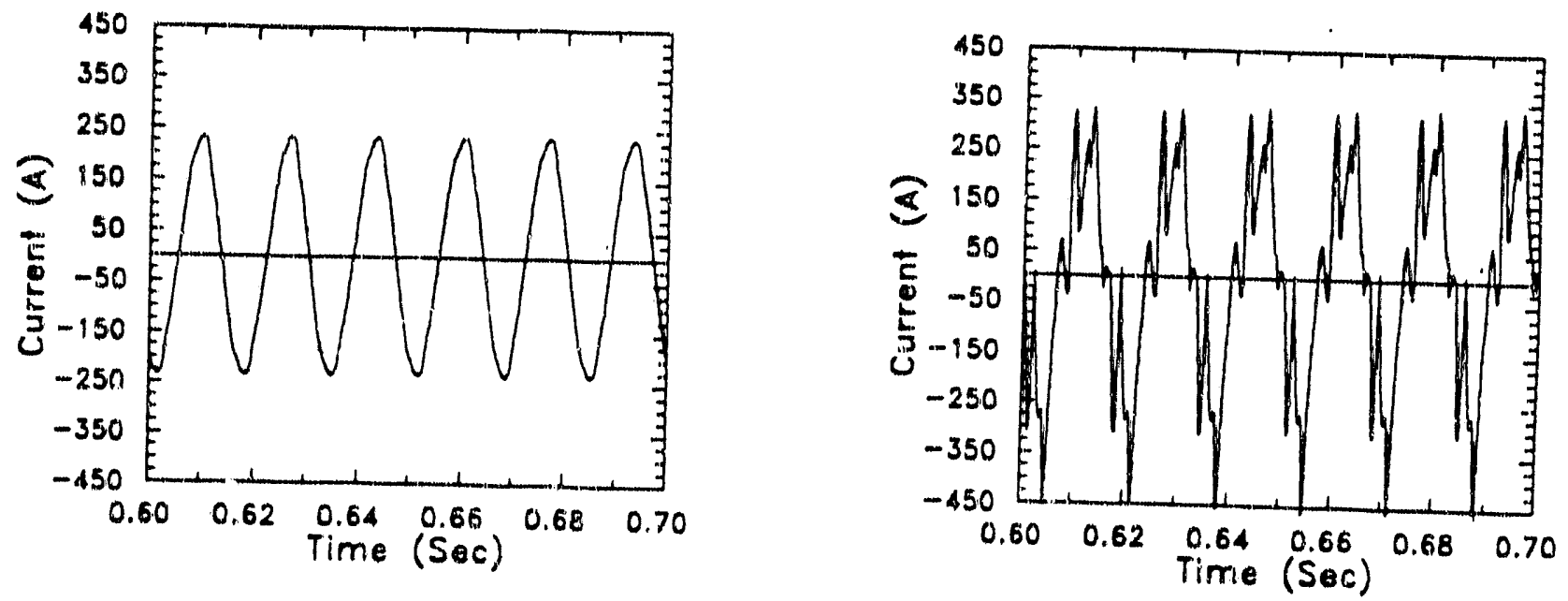

c. Secondary Current (Channel 8) for $0.0 \mathrm{~A} \mathrm{Dc}$

d. Secondary Current (Channel 8) for 5.5 A Dc

Figure 9. Examples of Measured Transient Currents for Different De Levels. 
The quick-look analysis consisted of plotting all the data files in such a way to show the behavior of the envelope of the curves. In this manner, the overall shape of the waveform amplitudes can be determined and the effects of saturation can be noted as a function of the dc current levels. As an example of these results, Figure 10 illustrates the envelope curves for the phase conductor current of Figure $9 \mathrm{~b}$. Although the details of the current waveshape are lost in these envelope plots, the initial turn-on of the dc excitation is clearly evident, with the current peaks growing to about $5.2 \mathrm{~A}$ with an associated time constant of the system on the order of one second. Later, at about $t=2$ seconds, the $\mathrm{dc}$ is switched off, and the envelope curve is noted to drop back to about $2.0 \mathrm{~A}$, a value consistent with the unexcited case of Figure 9a. At about 3.5 seconds the de injection is again turned on, and the response again grows and becomes nonlinear.

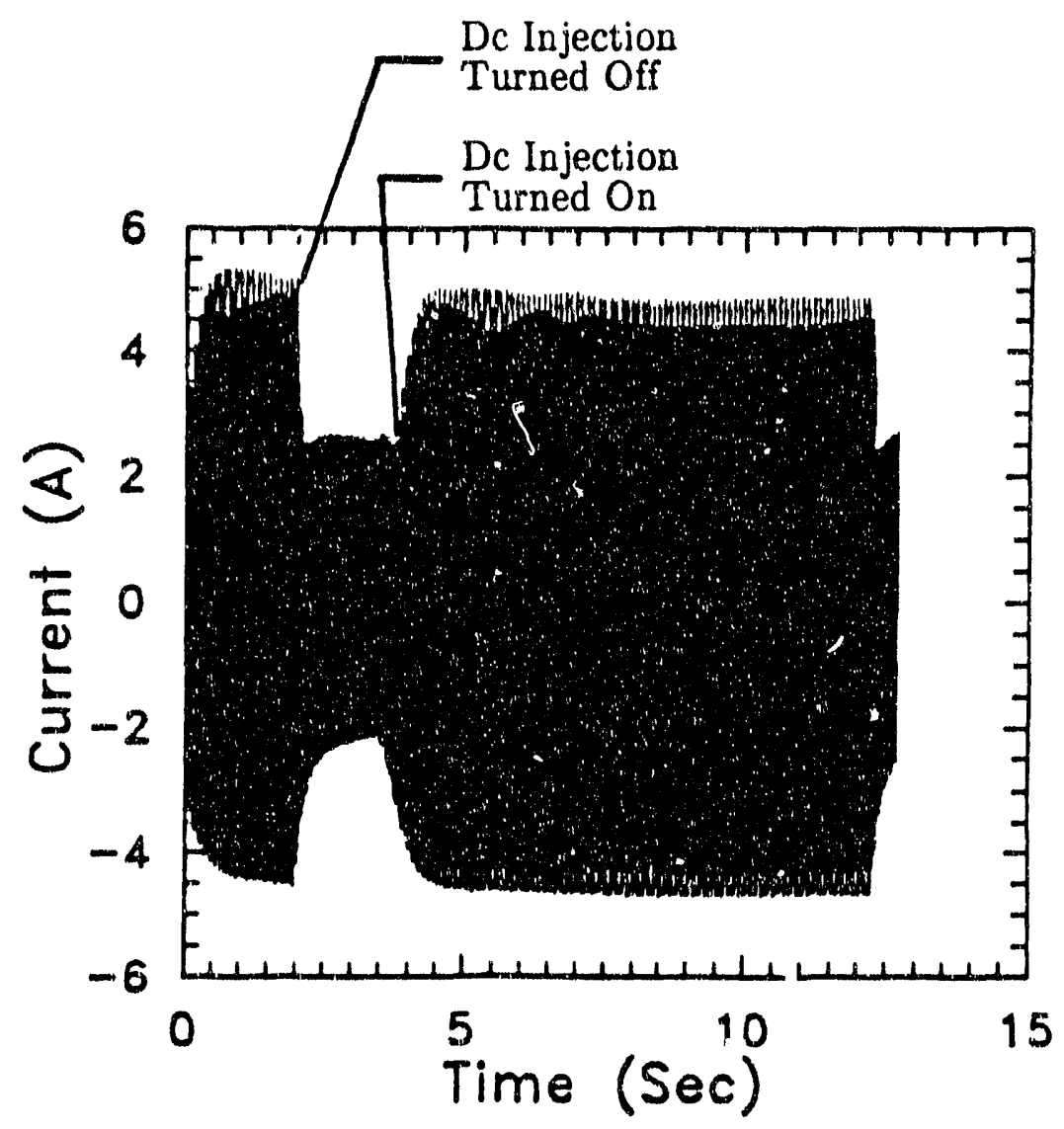

Figure 10. Example of the Envelope Plots for the Preliminary Analysis. 


\subsection{Harmonic Analysis}

The idea behind performing a harmonic content analysis of the measured data is to understand the time-dependent development of the $60-\mathrm{Hz}$ harmonics as the $\mathrm{dc}$ current injection is applied to the system. Clearly, the harmonic content of the waveform in Figure 9a will be significantly lower than in Figure 9b, and as the transformer transitions from one state to another, the harmonic content must undergo a smooth transition. It is useful to plot the transient behavior of these harmonics and show the rate of saturation of the transformer.

Figure lla shows the Fourier spectrum magnitude of the time domain current of Figure 9a. This was computed by using a discrete fast Fourier transform (FFT) involving 2048 time samples. It is presented as a continuous spectral density, with a vertical scale in units of $\mathrm{A} / \mathrm{Hz}$. Normally, a periodic function of infinite duration with a fundamental frequency of $60 \mathrm{~Hz}$ like those in Figure 9 will have a set of discrete spectral lines whose amplitudes are the coefficients of a Fourier series. Because the FFT calculation uses a windowed time function, the resulting FFT spectrum consists of a series of resonances of finite width. As the length of the time record increases, the width of these spectral lines decreases until true impulses are obtained for a record of infinite length.

To relate these calculated spectra to a Fourier series equivalent, it is necessary to multiply them by a factor " $f$ ", which is the sampling interval in the frequency domain [10]. This factor is inversely related to the maximum time of the transient waveform, and is equal to $2.44 \mathrm{~Hz}$ in the present case. Therefore, at the fundamental resonant frequency of Figure $11 \mathrm{a}$, the spectral component is about $0.9 \mathrm{~A}$. If the waveform of Figure 9a were analyzed analytically, assuming a perfect sinusoidal waveform, its $60-\mathrm{Hz}$ Fourier series coefficient would be about 1.0. This process serves as a check that the numerically calculated Fourier spectrum is being done properly.

The corresponding spectral density magnitude for the current of Figure $9 \mathrm{~b}$ is shown in Figure 11b. Here it is clear that the nonlinear behavior of the transformer has resulted in a waveform rich in spectral harmonics, occurring at multiples of $60 \mathrm{~Hz}$.

To process the entire 13 seconds of transient data, a sliding FFT window method was used. The FFT window consisted of 1024 sample points, with a total period of 0.204 seconds. This window started at the beginning of the waveform, i.e., at $t=0$, and moved along until the end of the total waveform was reached. This resulted in a totai of 64 FFT"s performed for each waveform. At each time step in the waveform, the Fourier series spectral lines at $60,120,180,240,300$, and $360 \mathrm{~Hz}$ were computed and saved. 


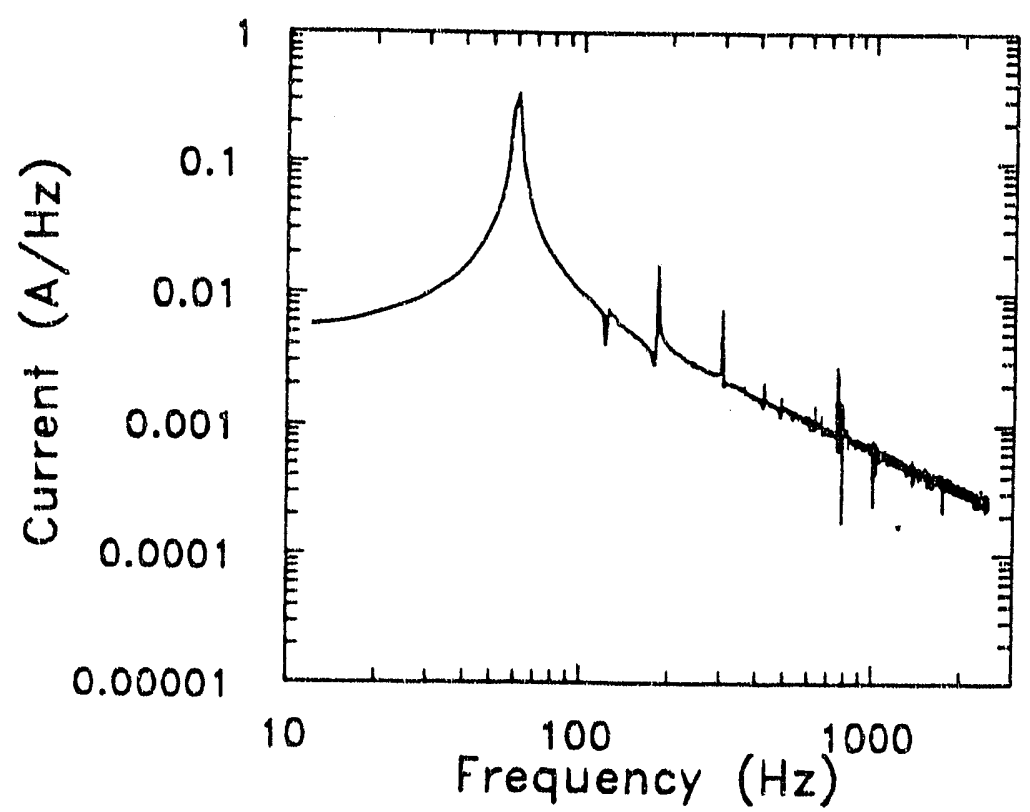

a. Primary Current With No Dc Excitation

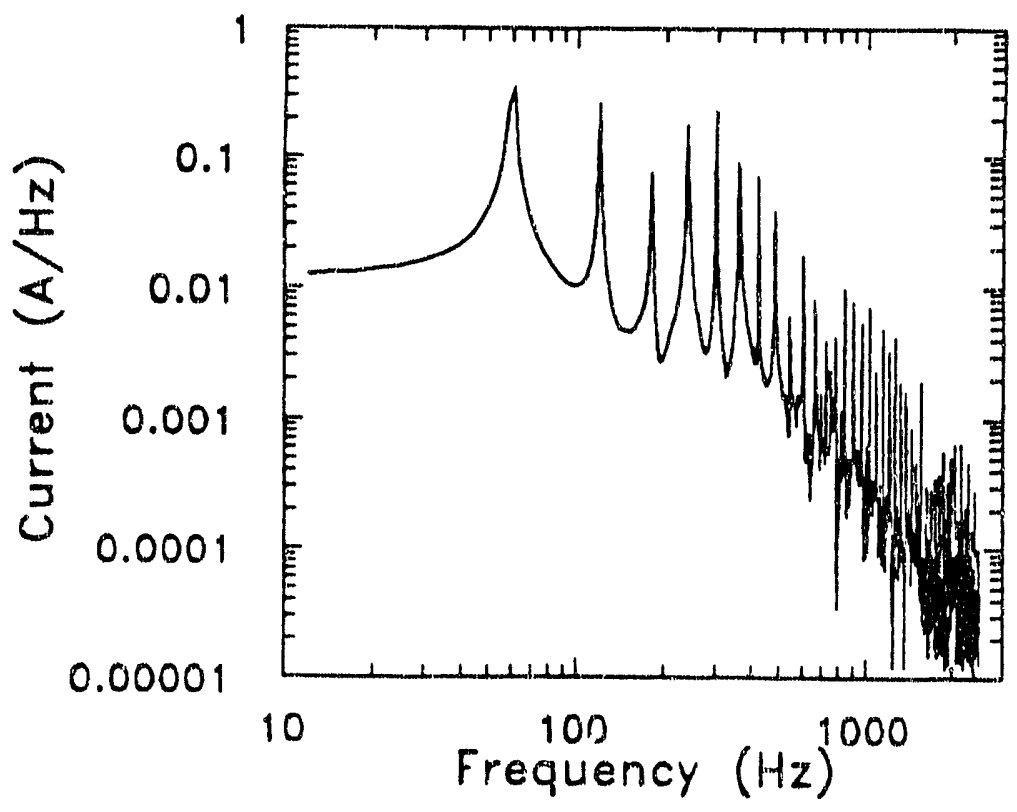

b. Primary Current With 5.5-A Dc Excitation

Figure 11. Examples of Computed Spectra for Measured Responses. 
The quick-look data processing did not include frequency-dependent probe corrections for to the low-frequency fall-off of the probe transfer impedances shown in Figure 8. Most of the voltage or current probes used in these tests were described by frequencyindependent calibration factors which simply scaled the measured probe responses. These factors were incorporated in the generation of the ASCII data files and subsequently used in the data processing. For data channels 2 and 4 , however, the T\&M Research current probes were used, and, as indicated previously in Figure 8 , corrections to the probe transfer impedance were required at frequencies below $200 \mathrm{~Hz}$ if an accurate determination of the harmonic content of the responses was to be obtained.

One way of correcting the probe transfer impedance is to simply digitize the impedance shown in the figure and provide a calibration table of probe impedance vs. frequency. Given a particular measured probe response, which is to be corrected at a frequency $f_{o}$, the appropriate complex-valued probe correction factor is interpolated from the data table and then divided into the probe response to obtain the corrected current. Note that this correction factor must involve both the magnitude and the phase of the probe transfer impedance, although only the magnitude function is shown in the figure. This approach is identical to many of the instrumentation probe correction procedures used for fast transient measurements for HEMP testing.

An alternative to interpolating from the data table is to use an analytical curve-fit to the measured probe transfer impedance function. An examination of the spectral magnitude function for the probe in Figure 8 indicated that the probe is behaving as a 1-pole high-pass filter at low frequencies. Using a network analyzer, a precise measurement of the lower 3-dB frequency of the probe was made by MRC using a variable frequency marker, giving a value of $116.8 \mathrm{~Hz}$, or about $740 \mathrm{radians} / \mathrm{second}$. Using this low-frequency break-point and the knowledge that the high-frequency asymptote of the probe impedance is about $0.45 \Omega$, the following 1-pole fit can be developed for the probe transfer impedance:

$$
Z_{1}(\omega)=\frac{(j \omega \times 0.45)}{(j \omega+740 .)}
$$

where $\omega$ is the angular frequency, $\omega=2 \pi f$. In the actual probe, there is an additional highfrequency fall-off, along with a possible probe resonance at $10 \mathrm{MHz}$, but because we are interested only in the low-frequency behavior of the probe, these high-frequency effects are not modeled here. 
The probe correction factor defined in Eq. (1) above is a complex-valued function, having both a magnitude and a phase component. Figures $12 \mathrm{a}$ and $12 \mathrm{~b}$ present these quantities as determined from the above expression, both shown as a function of frequency. The magnitude of $Z_{\mathfrak{t}}$ at $f=60 \mathrm{~Hz}$ is seen to be about $0.20 \Omega$, which confirms the validity of Eq. (1).

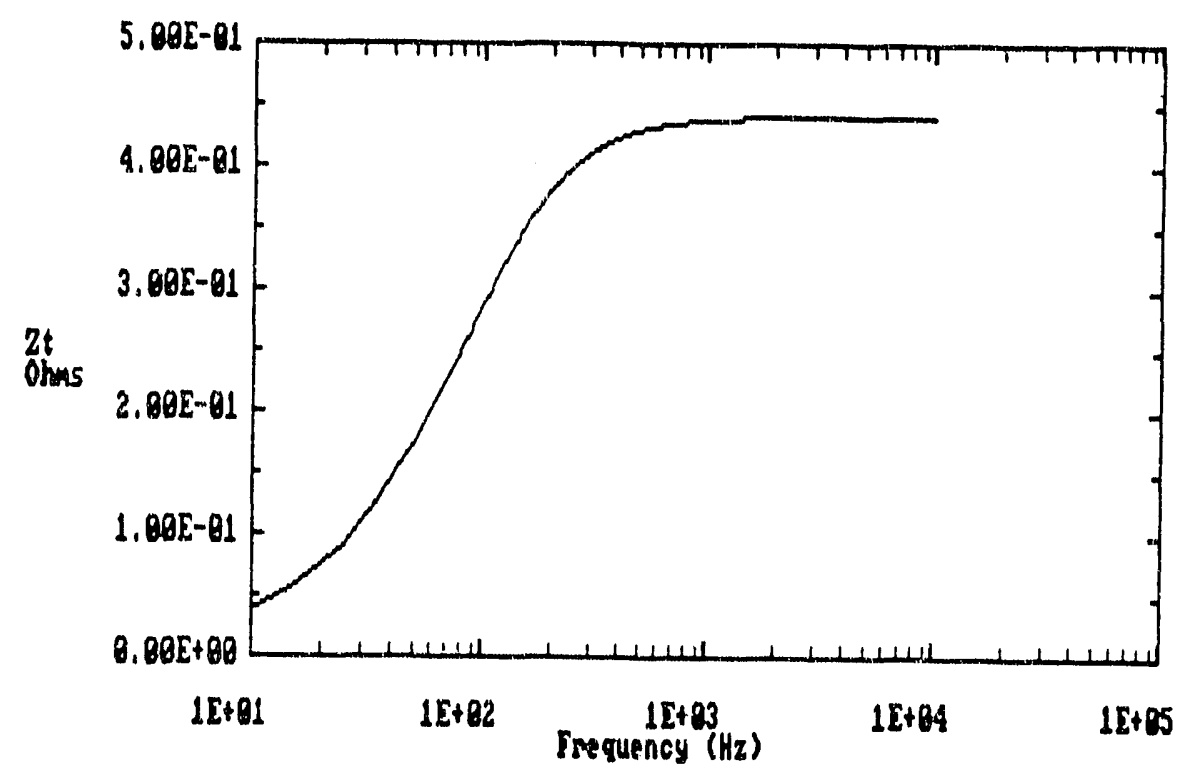

a. Magnitude

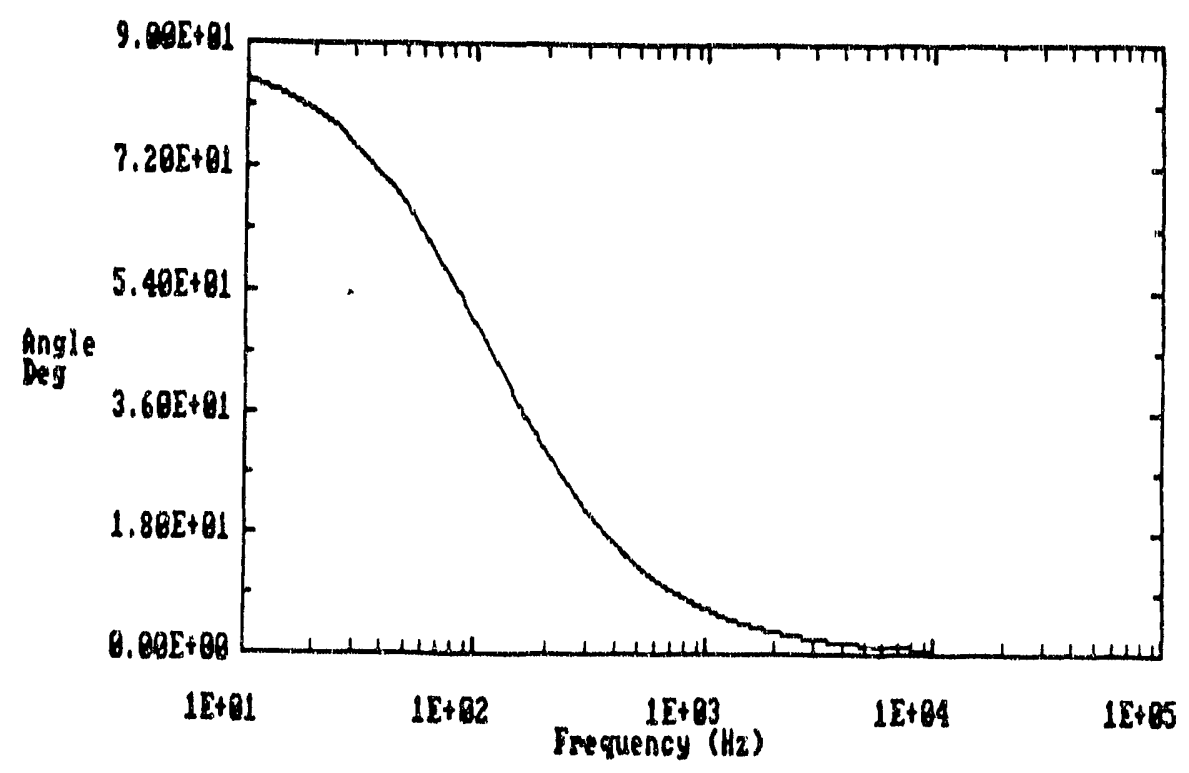

b. Phase Angle

Figure 12. Plots of the Analytical Current Probe Impedance Function. 
Figure 8 shows that the magnitude of $Z_{t}$ at the same frequency is slightly different, having a measured value of about $0.26 \Omega$. This difference arises from the fact that the $3-\mathrm{dB}$ frequency point of $f_{3 \mathrm{~dB}} \approx 90 \mathrm{~Hz}$ taken from the curve in Figure 8 is different from that of $f_{3 \mathrm{~dB}} \approx 116.8 \mathrm{hz}$ obtained by measuring this frequency directly with the marker in the network analyzer. The discrepancies between these two $3-\mathrm{dB}$ frequencies indicate that there is also some uncertainty in the probe calibration process, a fact that will be evident when an energy balance is performed later in Section 6.4 of this report.

As an example of the effect of the frequency dependence of this probe correction function, the response shown in Figure $11 \mathrm{~b}$ has been reprocessed using the probe transfer impedance of Eq. (1). Figure 13 shows the resulting current spectrum, corrected for the lowfrequency probe fall-off. This spectrum exhibits a definite increase in the low-frequency response, as expected from the probe characteristics.

To illustrate this probe correction procedure on the measured spectral harmonics of the line current, the time history of the primary $60-\mathrm{Hz}$ spectral coefficient and the next 5 harmonics is shown in Figure 14a for the case of no dc injection into the transformer. The primary-side current is significantly larger at $60 \mathrm{~Hz}$ than at the higher harmonics, and the relative ratios of the harmonics appear to be constant as time progresses. For the case with $5.5 \mathrm{~A}$ of dc injection, Figure 14b shows the associated spectral content. As discussed earlier, the dc injection was switched off at about $t=2$ seconds, and turned on again at about $t=3.5$ seconds. The effect of this procedure on the spectral content is clearly evident. Note that the 60- $\mathrm{Hz}$ spectral component is slightly affected by this dc excitation (see the slight dip at $\mathrm{t}=2$ seconds).

\subsection{Power Analysis}

As mentioned previously, simultaneous voltage and current measurements were made on phases 1 and 2 of the high-voltage side of the first transformer and on all three phases of the terminating resistors of the loads. Consequently, these measurements can be used to infer the amount of complex power flowing on the lines and into the load. Unfortunately, for the high-voltage section on phase 3 , only the voltage was measured, so its power cannot be determined directly. In addition to making these power measurernents, we placed a Dranetz. Power Demand Analyzer at the source end of the transformers, and were thereby able to monitor both real and reactive powers on all phases. 


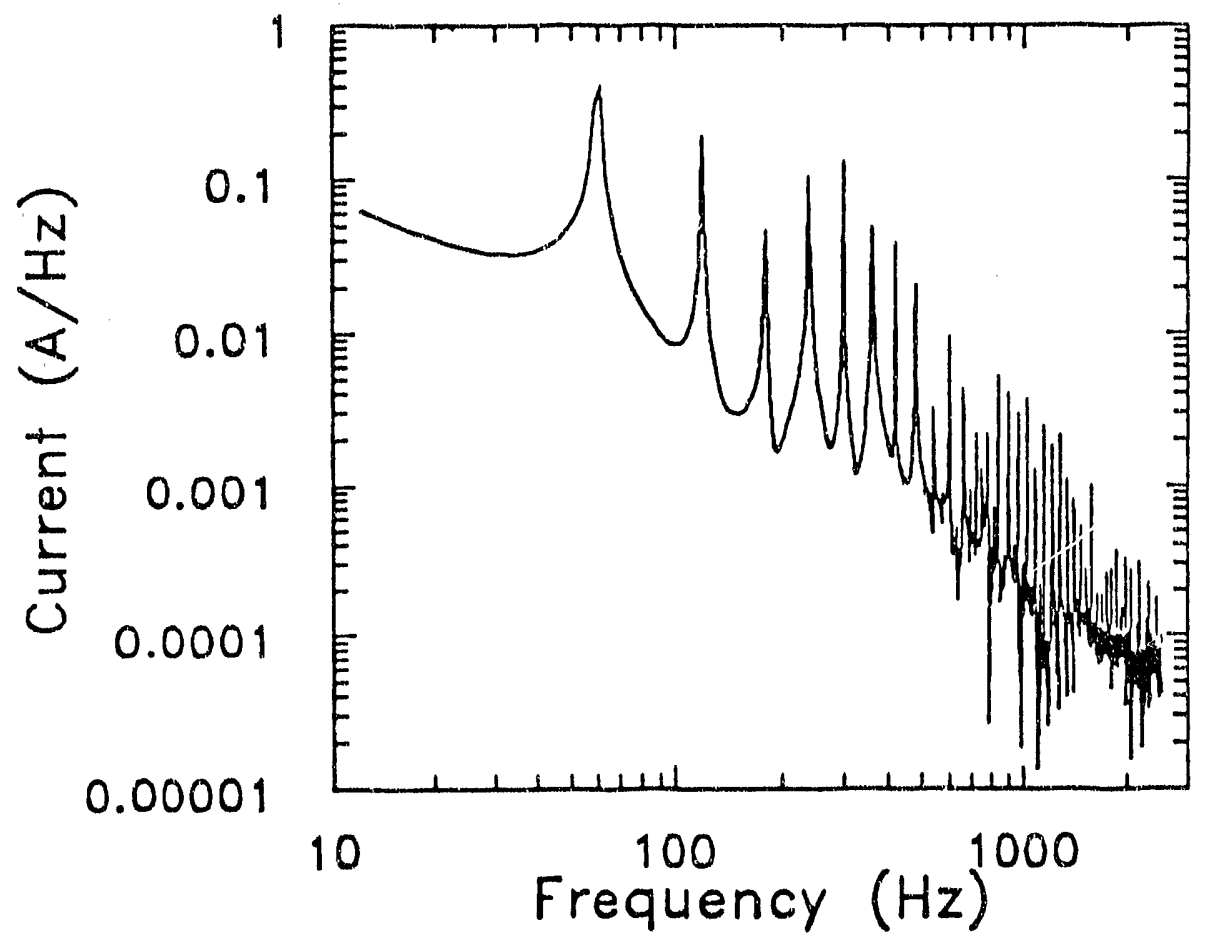

Figure 13. Corrected Spectrum of Fig. $9 \mathrm{~b}$ Using the Probe Correction Function of Fig. 12. 


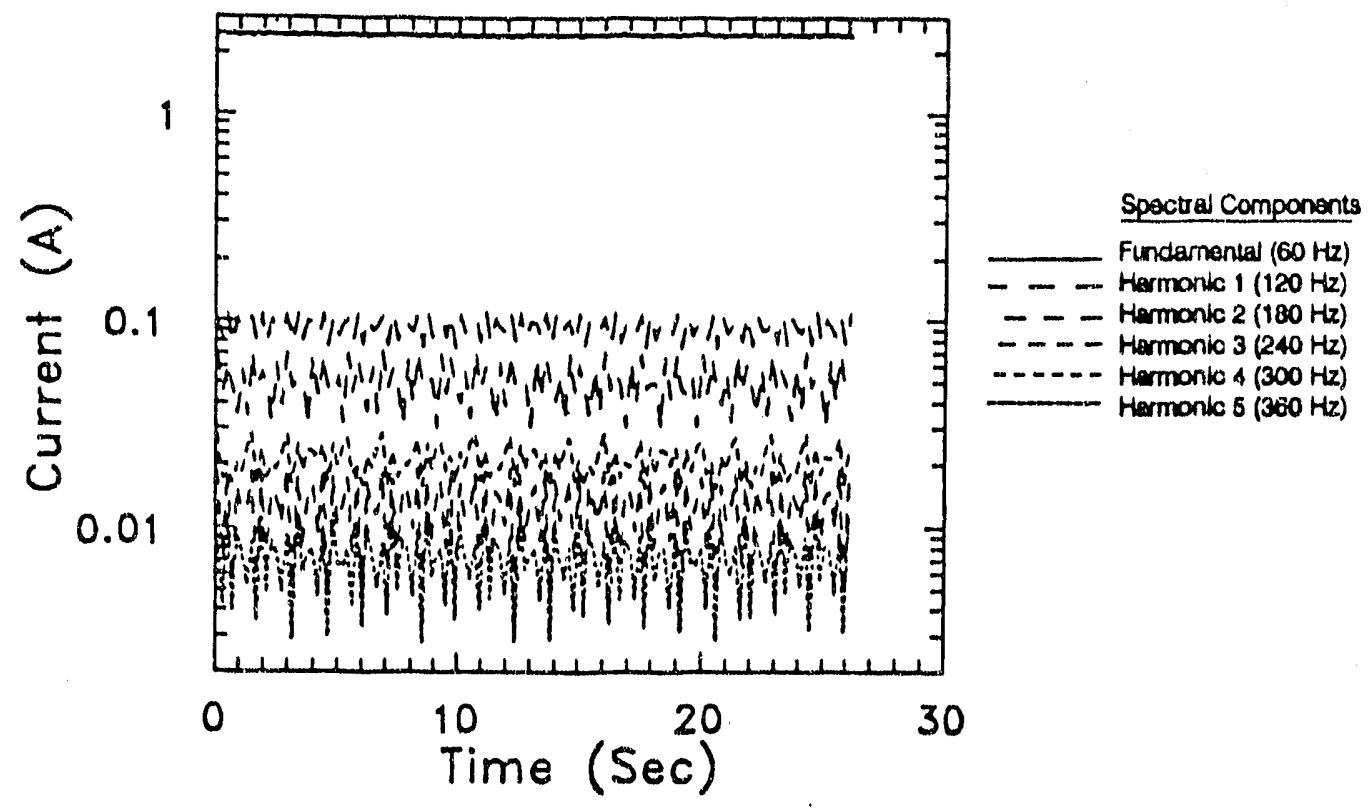

a. No Dc Excitation.

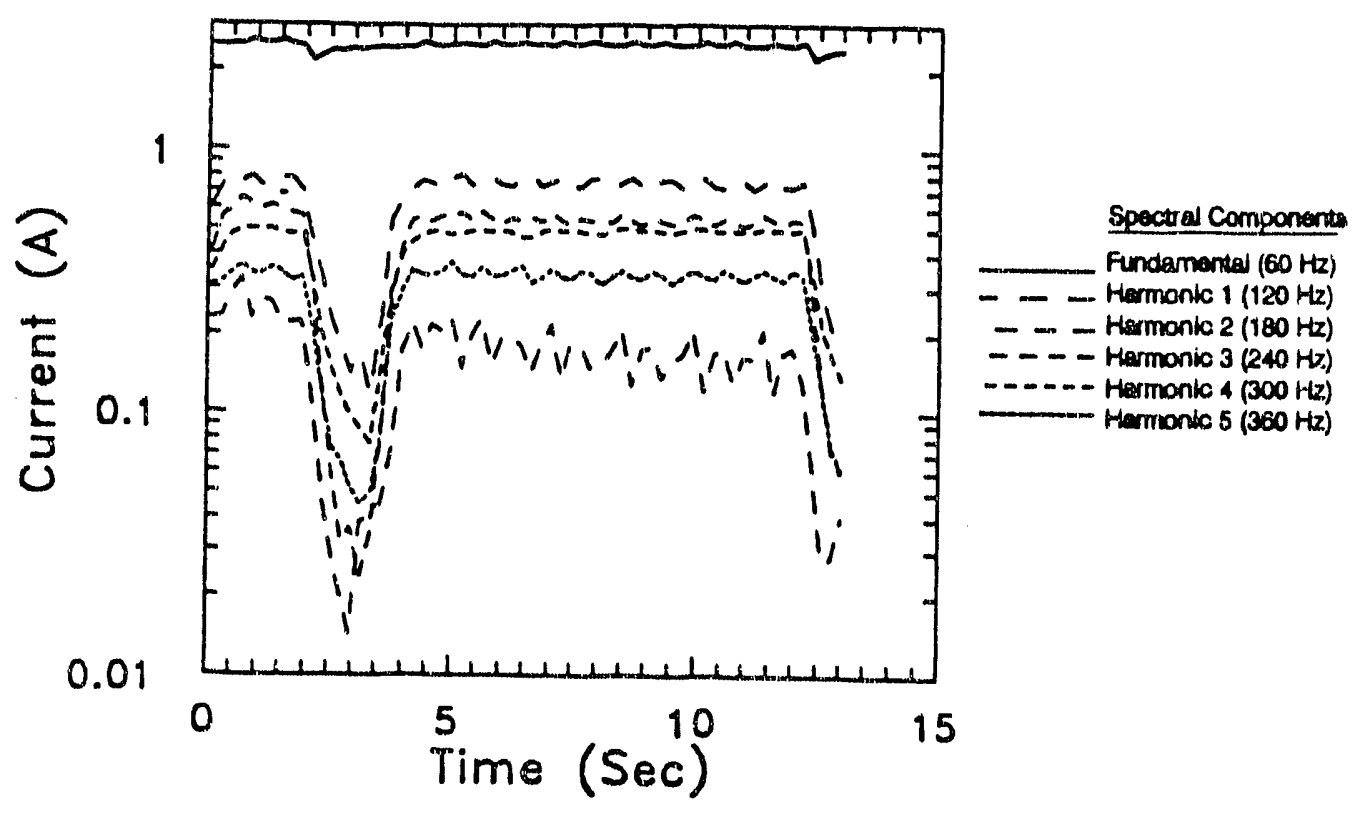

b. 5.5 A Dc Excitation

Figure 14. Examples of Principal Harmonic Content for Measured Waveforms. 
At a particular frequency $\omega$ the complex power is defined in terms of the peak voltage and current phasor components as

$$
P(\omega)=1 / 2 I(\omega) V^{*}(\omega) \quad(W)
$$

Relating these phasors to the computed spectral component at $60 \mathrm{~Hz}$ permits the estimation of the delivered power at $60 \mathrm{~Hz}$. Note that Eq. (2) defines a complex power, the value of which is critically dependent on the phase relationship between the measured voltage and the current.

Applying Eq. (2) to the voltage and current measurements at the $208-\mathrm{V}$ side of the T2 transformer provided estimates of the power delivered to the loads. These could be compared with the input power measurements from the power demand meter in the source circuit. Good agreement in these comparisons was noted.

However, for the checks on the power flow on phases 1 and 2 in the high-voltage section of the line, between $\mathrm{T} 1$ and $\mathrm{T} 2$, it was found that the agreement was not satisfactory. As an example, Figure 15a presents the measured $60 \mathrm{~Hz}$ power, both real (watts) and imaginary (vars), as a function of time for the $0.0 \mathrm{~A}$ dc injection case for configuration $1 \mathrm{~A}$. The power demand meter in this case registered a real power of approximately $19.1 \mathrm{~kW}$, with 0.0 var. The real power in this figure is approximately correct, but the reactive power is too large. This error arises due to the uncertainty in the measured data for the low-frequency probe correction, as discussed previously.

In the absence of additional probe characterization data, a remedy to this problem was sought by modifying the probe transfer impedance so as to provide the proper power calculations at $60 \mathrm{~Hz}$. This was done by multiplying the probe transfer impedance by the complex quantity $(0.90-\mathrm{j} 0.37)$. Figure $15 \mathrm{~b}$ illustrates the resulting $60 \mathrm{~Hz}$ power in this case. Note that the computed reactive power is now consistent with that measured from the power demand meter.

Figure 16 presents the computed $60-\mathrm{Hz}$ power as a function of time for phase 1 (channels 1 and 2) for the case of the 5.5-A dc injection that has been discussed previously. Notice that the presence of the do excitation places a very significant reactive power demand on the generator feeding the transformers. 


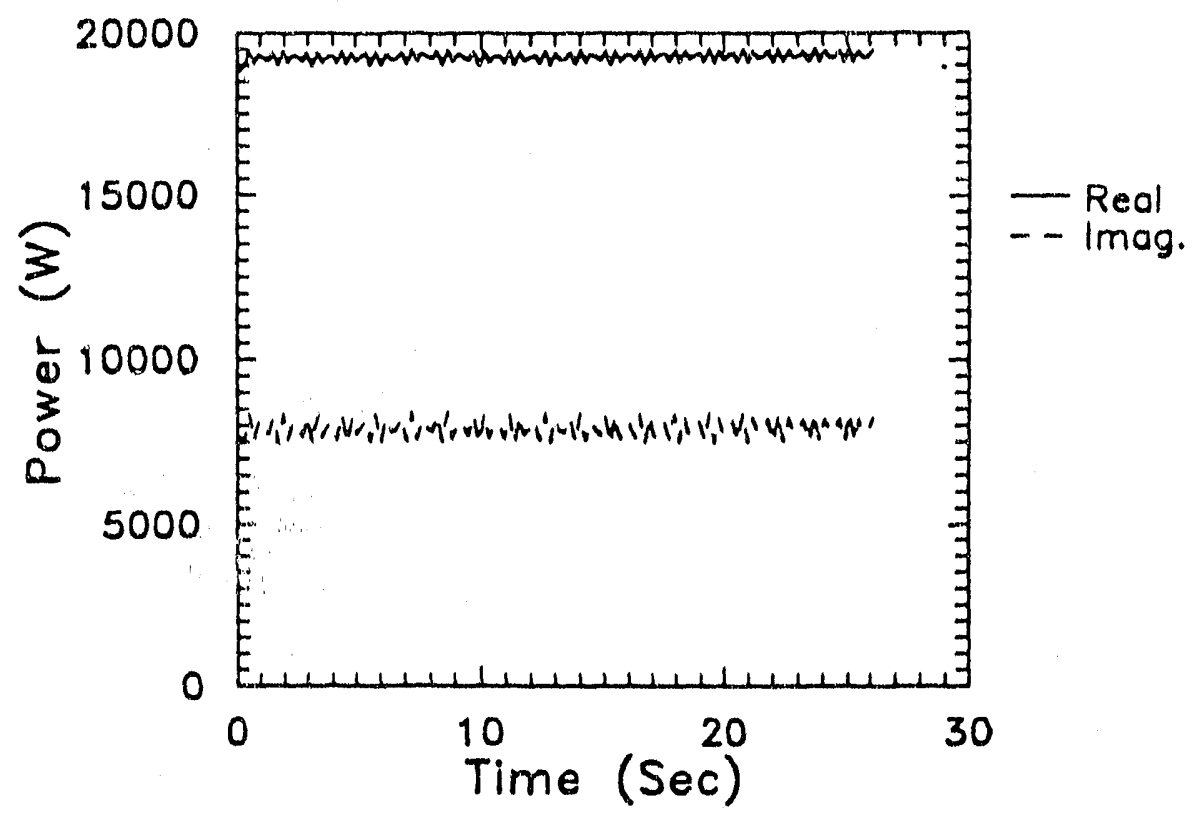

a. Uncorrected Power

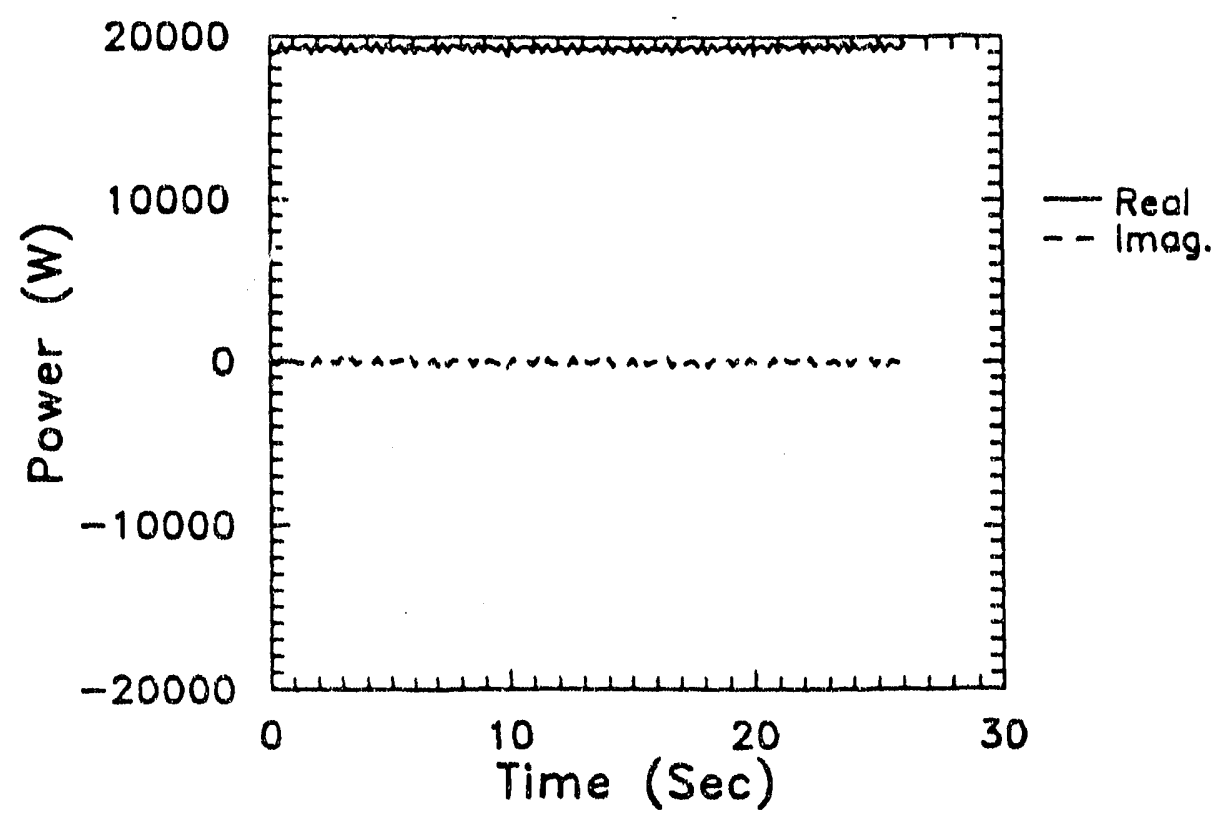

b. Corrected Power

Figure 15. Complex 60-Hz Power Computed for Phase 1 with No Dc Excitation. 


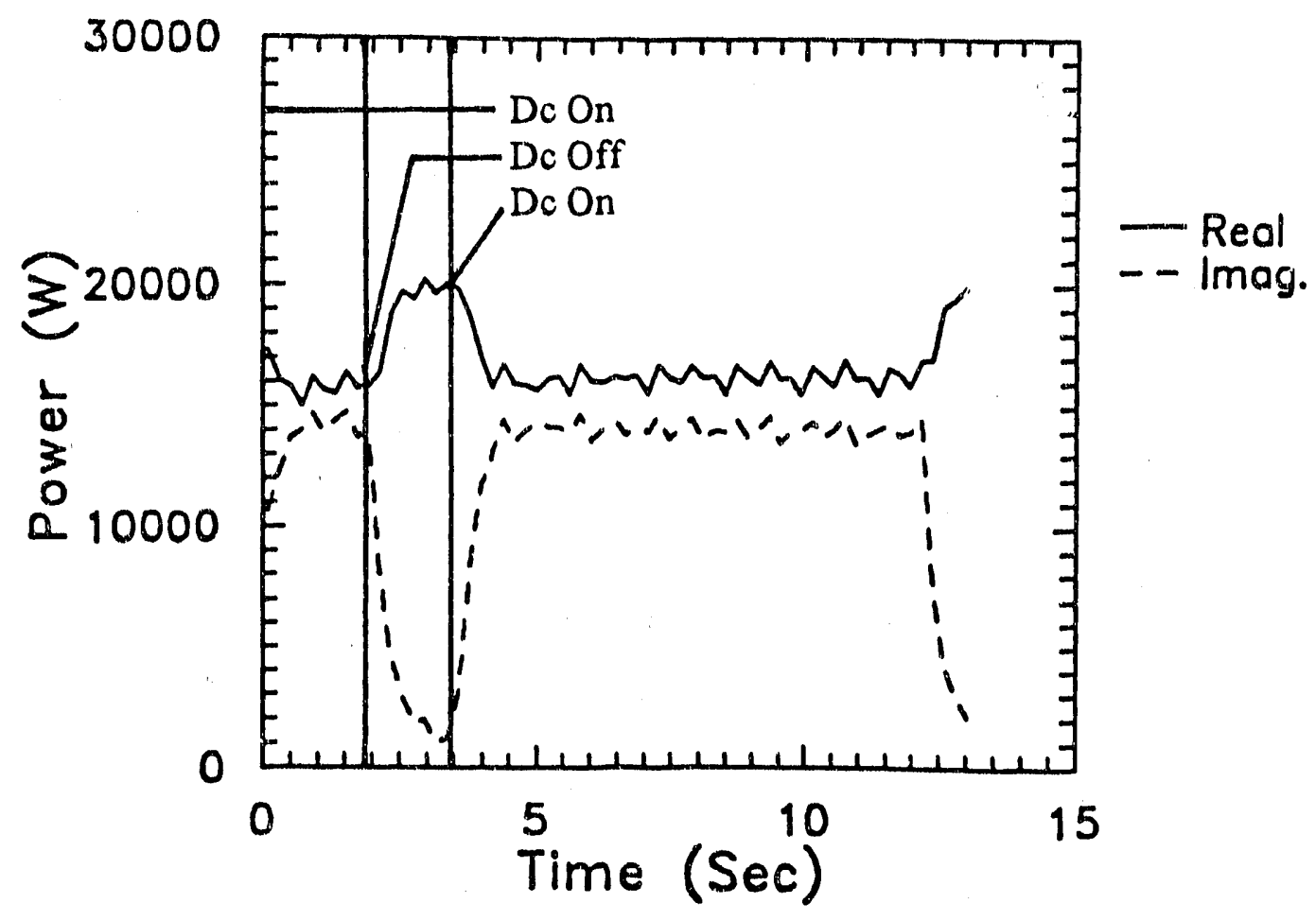

Figure 16. Complex Power for Phase 1 Configuration 1A, With 5.5 A Dc Excitation Switched On, Off, and On. 


\subsection{OBSERVATIONS FROM THE TEST DATA}

From the data taken in this test, a number of observations regarding transformer operation under a combined $\mathrm{dc}$ and ac excitation can be made. This section will summarize some of the important observations for the data and will discuss selected highlights of the responses.

\subsection{Configuration $1 \mathrm{~A}$}

The first case to be discussed is configuration 1A. As shown in Figure 2, this consists of two $Y-Y$ transformers with the neutrals grounded, and with the possibility that a dc current could be injected in the neutral of the primary circuit. It is of interest to observe the behavior of the phase current and the phase-neutral voltage on the $12.47-\mathrm{kV}$ section of the line for varying levels of dc injection. For no dc injection, as noted in Figure 9, the line current response consists simply of the normal $60-\mathrm{Hz}$ phase current. As the dc current level increases, the line current exhibits abnormal behavior. Figure 17 shows the envelope plots for the line current on phase 1 for de current injections of $0.0,0.6,1.0,1.5,3.0$, and $5.5 \mathrm{~A}$. As discussed in the previous section, these envelope curves have been determined using the scalar (i.e., frequency independent) current probe calibration factors. As such, they can only provide a qualitative indication of the current behavior.

For these injection tests, the ac power to the transformer was turned on, and several seconds later the dc battery source was applied. The data recorder was activated after the dc was applied, so that the complete turn-on transient response due to the dc injection is not always evident in the measurements. Later, two to three seconds into the test, the dc power was removed from the neutral circuit in such a way that neutral current could continue to flow. This dc excitation was then restored several seconds later.

The 5.5-A case in Figure 17 shows clearly the various stages of the response caused by applying the dc excitation. The initial turn-on transient is evident, as is the turn-off of the excitation at about $t=2$ seconds. It is interesting to note that there appears to be an $L / R$ time constant associated with this overall envelope shape which is a function of the dc current injection level. The observed relaxation times of this envelope appear to be much shorter as the do levels increase. With the ac power removed, as seen in the 1.0-A case where an ac fuse blew, the system response dies very quickly to zero with no ac excitation. In this case, the expected $1 / 3$ of the $1.0-\mathrm{A}$ dc injection current flowing in the phase 1 conductor is not registered, because of the low-frequency fall-off of the probe response and its subsequent inability to accurately measure dc currents. 

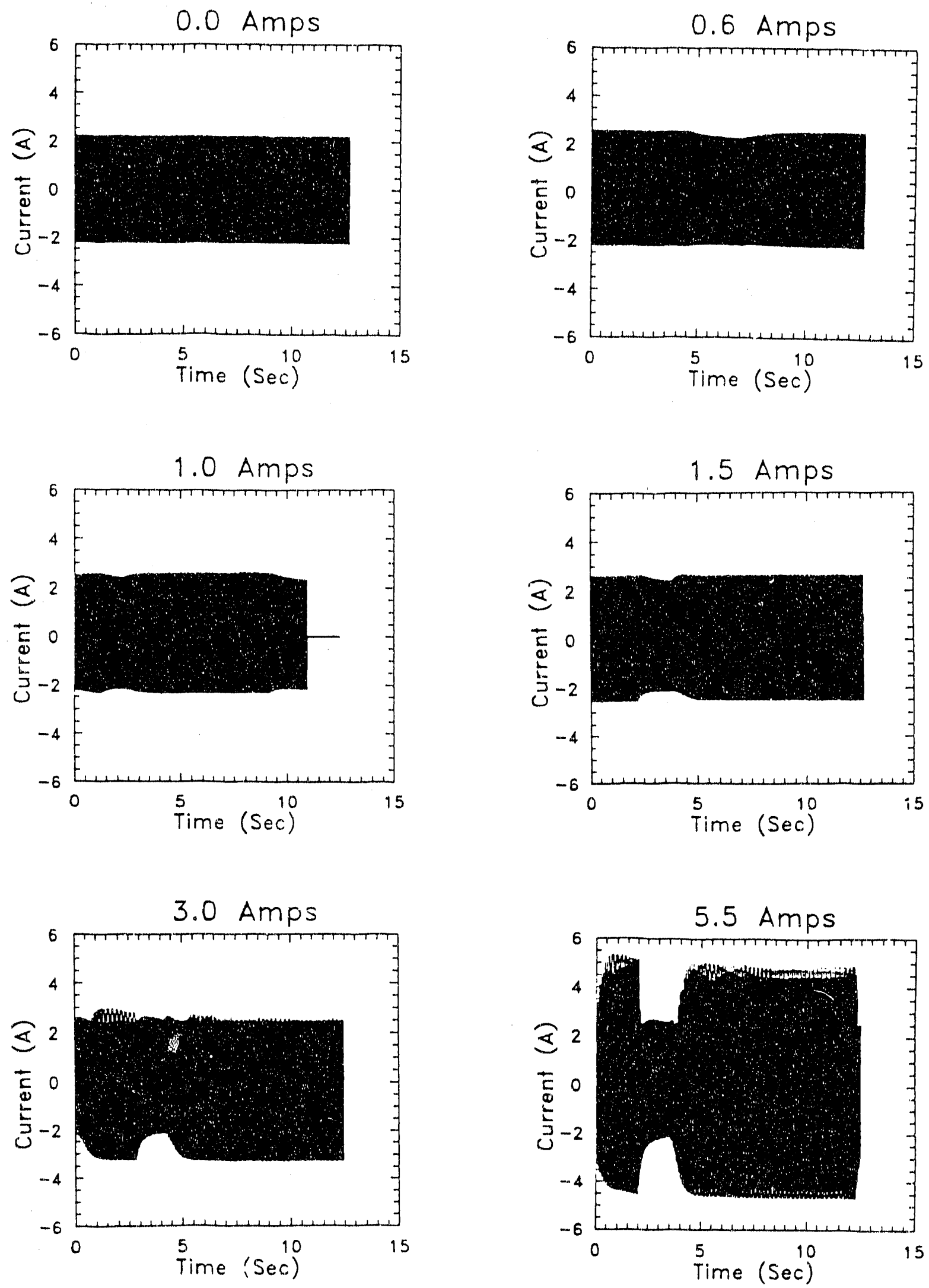

Figure 17. Envelope Plots of the 12.47-kV Phase 1 Current for Configuration 1A for Different Levels of Dc Injection Switched On, Off, and On. 
Figure 18 presents the corresponding phase 1 to neutral voltage (Channel 1) on the $12.47-\mathrm{kV}$ section of line for the six different levels of dc current injection. There is a noticeable change of this quantity as a function of the dc levels, but this change is not as large as the change in the line current.

The 3.0-A case shown in Figure 17 exhibits a noticeable asymmetry about the zero current axis. As the dc level increases, the degree of asymmetry decreases but is still present. This suggests the possibility that each phase of the line has a different response. Figure 19 shows a comparison of the phase 1 and phase 2 currents (measured in Channels 2 and 4 , respectively) for $0.0,3.0$ and $5.5 \mathrm{~A}$ dc injection. Unforiunately, the phase 3 currents were not measured. As noted in the zero dc excitation case, there is a considerable imbalance of the ac phase current envelopes with a noticeable baseline shift for the phase 2 response. For the 3.0A injection, there is a distinct difference between the two-phase current envelopes, but as the dc current level increases, these envelopes become more alike. In theory, this effect might be caused by the different saturation states of the three transformer cores for low leveis of applied dc excitation.

The behavior of the neutral current envelopes from Channel 6 is shown in Figure 20 for the six levels of dc injection. It is clear for under no dc excitation the neutral current is quite small, indicating that the three phases of the power system are well balanced. With the application of a small arnount of dc however, there is a marked increase in reutral current. Even a 0.6-A dc injection causes peak neutral currents on the order of 8-A to flow. This increase in the neutral current is presumably caused by the different saturation of the transformer cores, which causes a system imbalance. In adidion, the harmonic content for these neutral currents is significantly higher than that for the currents on the phases. In fact, with the exception of the $0.0-\mathrm{A}$ dc case, the harmonics in the neutral current at 180 and 300 $\mathrm{Hz}$ were larger than the fundamental component at $60 \mathrm{~Hz}$. It is interesting to note that in these cases, the peak value of the neutral current is significantly larger than either the peaks of the phase conductor currents or the injected dc current. This larger peak is caused by the high harmonic content in the neutral current waveform, which arises from the core saturation. 

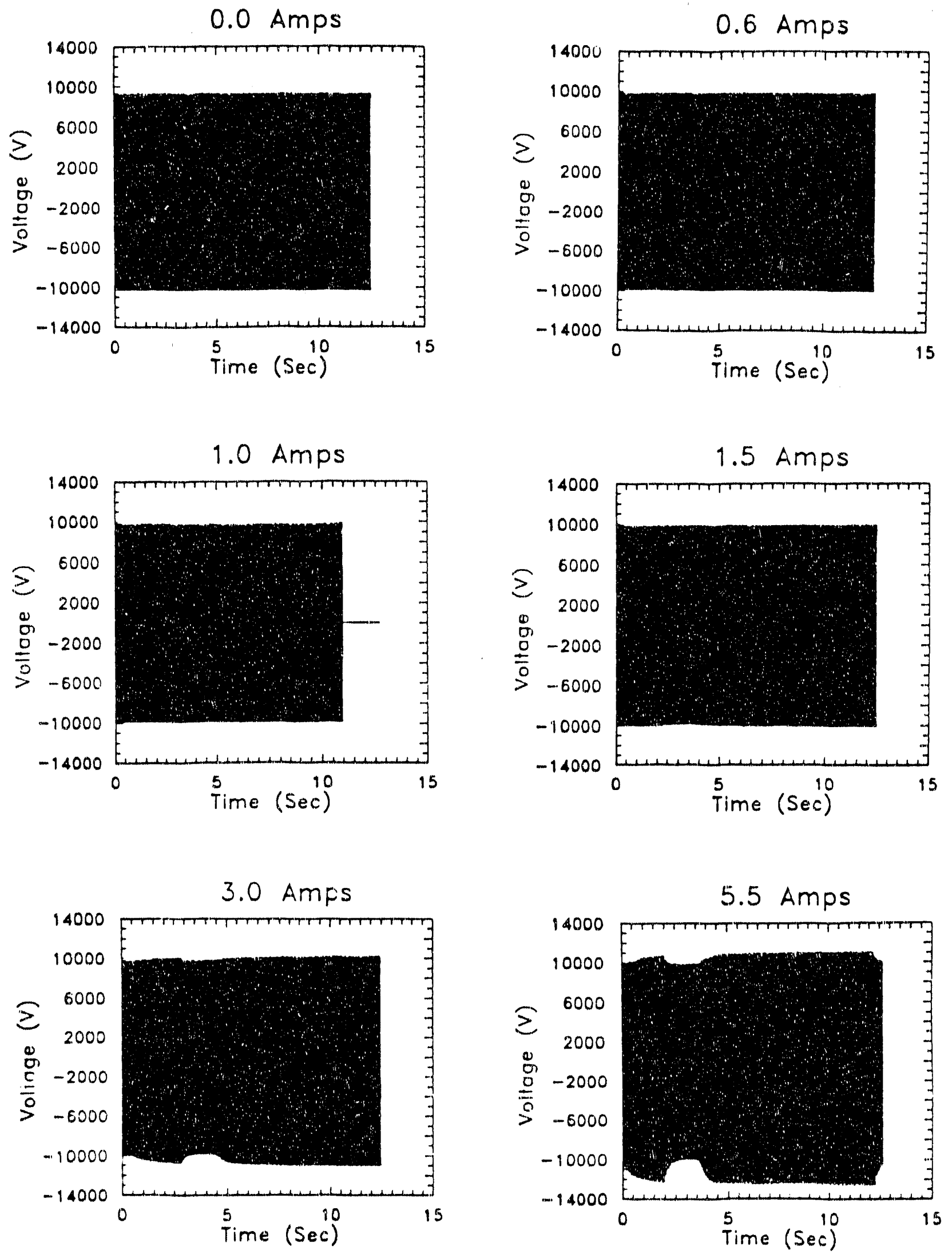

Figure 18. Envelope Plots of the $12.47-\mathrm{kV}$ Phase 1 Voltage for Configuration $1 \mathrm{~A}$ with Different Levels of Dc Injection Switched On, Off, and On. 
PIIASE 1
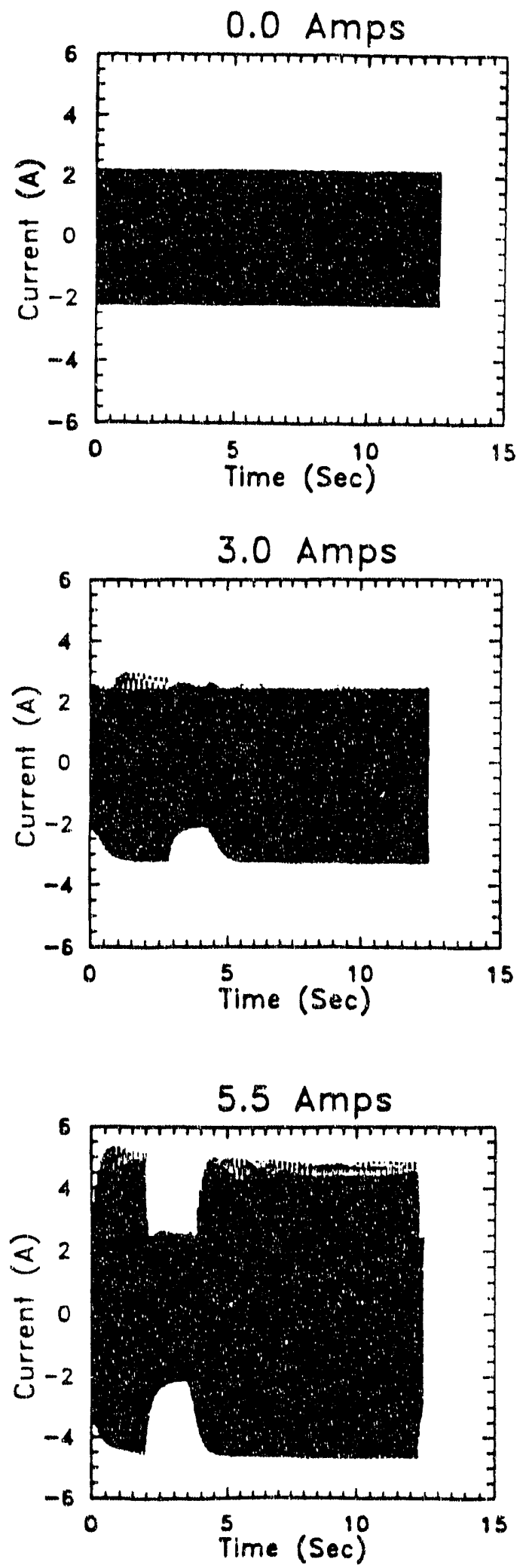

PIIASE 2
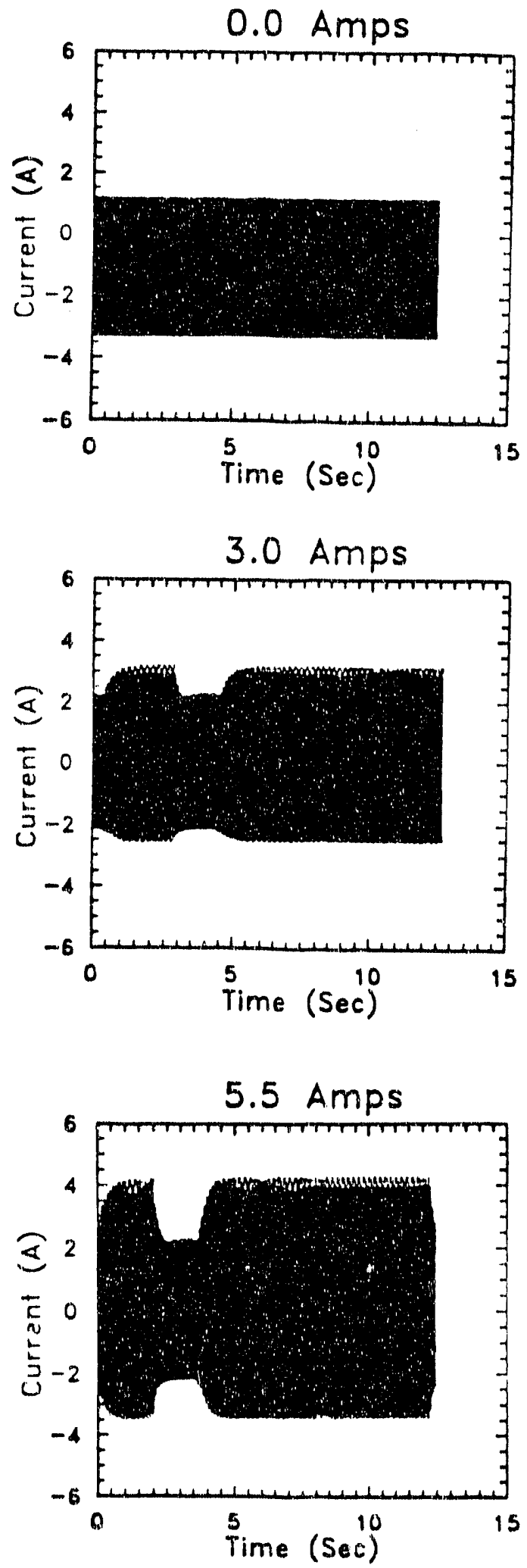

Figure 19. Envelope Plots for Phases 1 and 2 Currents for Various Levels of Dc Injection Switched On, Off, and On (Phase 3 Not Measured). 

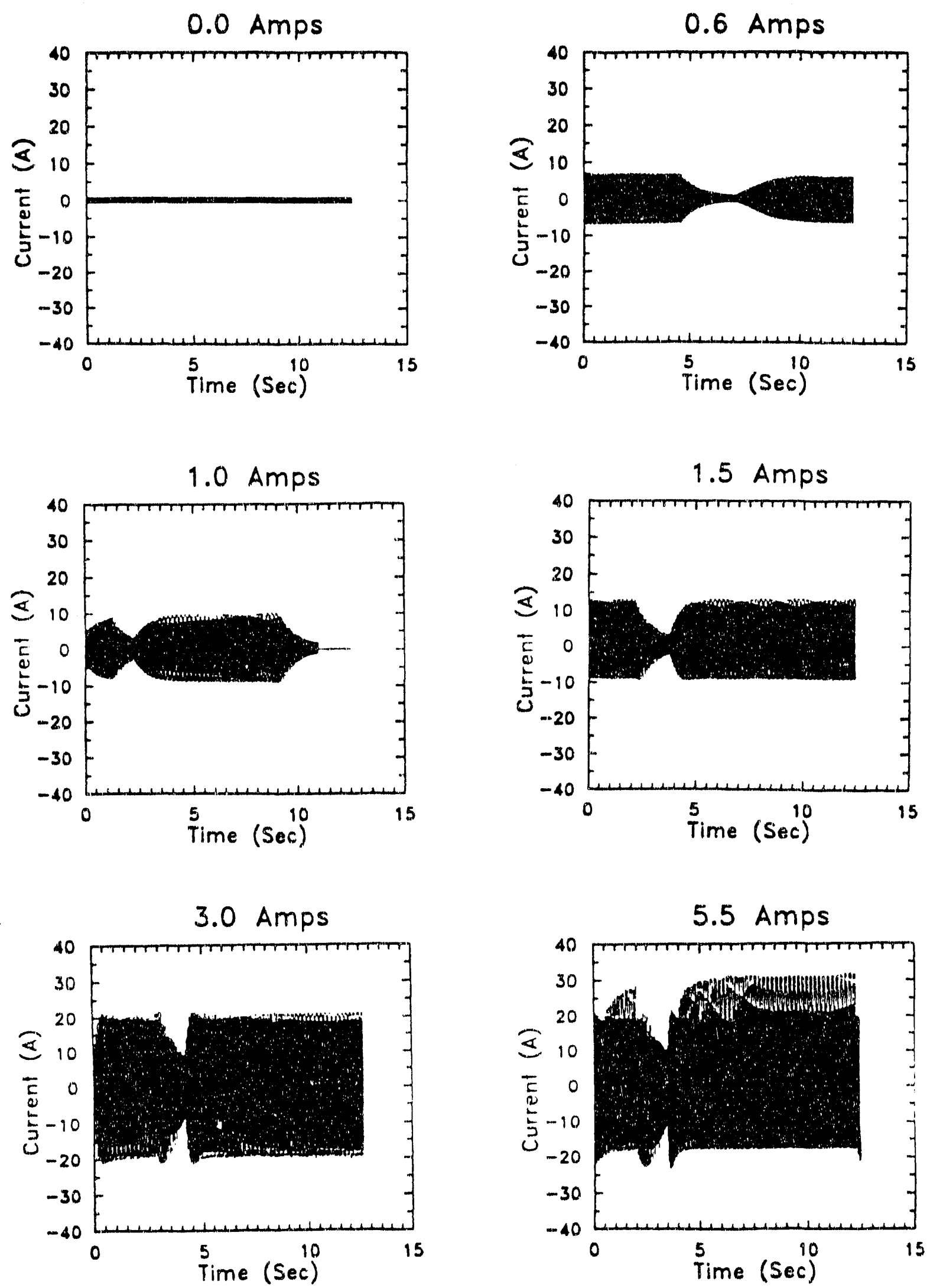

Figure 20. Envelope Plots for the Neutral Currents in the $12.47-\mathrm{kV}$ Line for Various Levels of $\mathrm{Dc}_{\mathrm{c}}$ Injection Switched On, Off, and On. 
Figure 21 illustrates the behavior of the load current envelopes at the secondary side of the second transformer for 0.0 and $5.5 \mathrm{~A}$ dc injection. Although the load currents are more or less balanced when there is no dc injected into the transformers, the load currents on the $208 \mathrm{~V}$ side become unbalanced in the presence of the dc excitation. This observation, as well as that concerning the neutral current, suggests that the saturation characteristics of each phase of the transformer core are slightly different.

\section{Spectral Analysis}

As mentioned in the previous section, the behavior of the envelope curves does not tell the complete story of the voltage or current behavior, because these waveforms consist of a number of harmonic components as well as the $60-\mathrm{Hz}$ fundamental component. Using the spectral processing method discussed previously, the harmonic content of the $12.47-\mathrm{kV}$ phase 1 current and voltage has been computed and is plotted in Figure 22 as a function of the cic current injection. As was noted in Figure 18, the harmonic content of the line voltage is not as sensitive to the dc current injection as is the line current, which exhibits a continual increase in all of the harmonics as the do injection increases. The $60-\mathrm{Hz}$ fundamental component of both the current and voltage appears to be rather insensitive to the dc injection, however.

\section{Reactive Power Demand}

It is of interest io determine the change in reactive power flowing in the system, and the especially the possible increase in the reactive demand placed on the generation facilities by an increase in the dc injection level. This amounts to determining the change in the phase angles between the voltage and current $60-\mathrm{Hz}$ spectral components as the do level varies. From the complex power computed using the phase 1 voltage and current spectra, the increase in reactive power on phase 1 is illustrated in Figure 23a. There is a nearly linear fit to the reactive demand as a function of the dc injection. At the injection level of $5.5 \mathrm{~A}$, the reactive power is about $15 \mathrm{kvar}$. For the $0.0 \mathrm{~A}$ dc injection, the normal power per phase is about $18 \mathrm{~kW}$. This increase in reactive power can pose a considerable problem for come generation equipment.

Figure 23b shows the behavior of the reactive power for very small levels of dc injection. For the cases of $0.0,0.06$ and $0.1 \mathrm{~A}$ of $\mathrm{dc}$ injection, the reactive power increase was essentially zero. Above $0.1 \mathrm{~A}$, the reactive power begins to increase linearly. Thus, it appears that the limit of linear operation for this particular configuration is at about $0.1 \mathrm{Adc}$. 
$0.0 \mathrm{~A} \mathrm{Dc}$ Injection
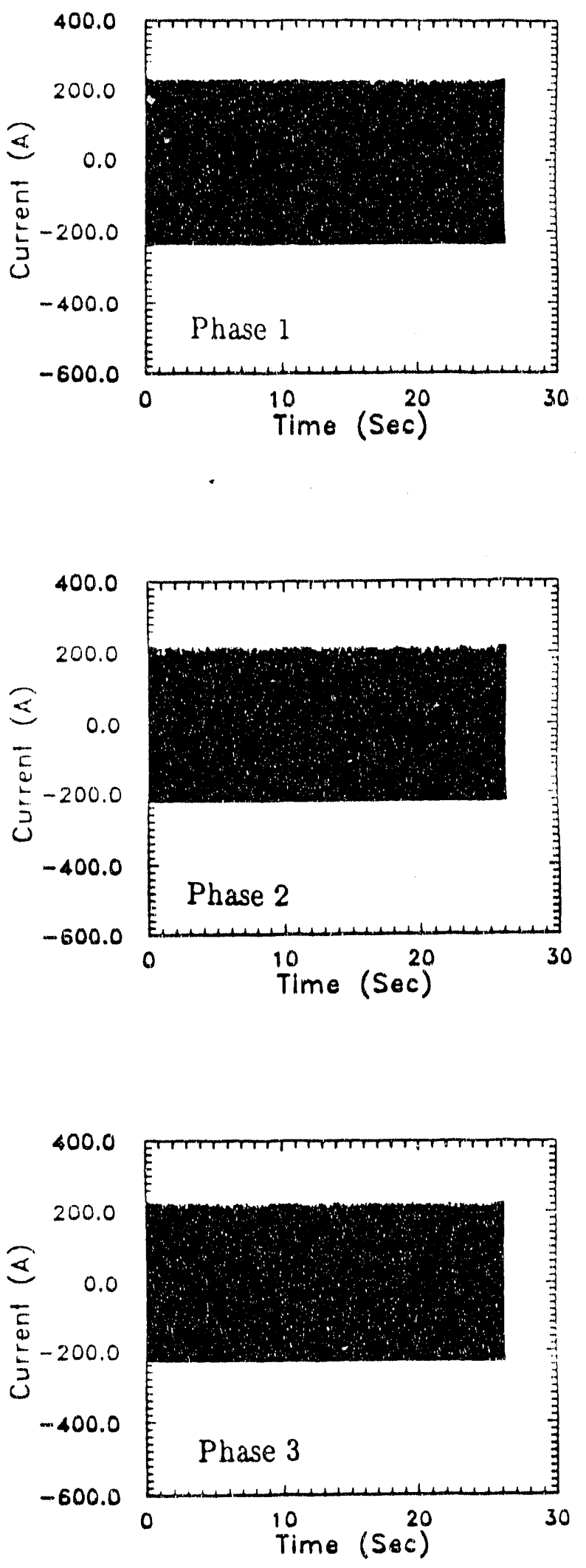

5.5 A Dc Injection
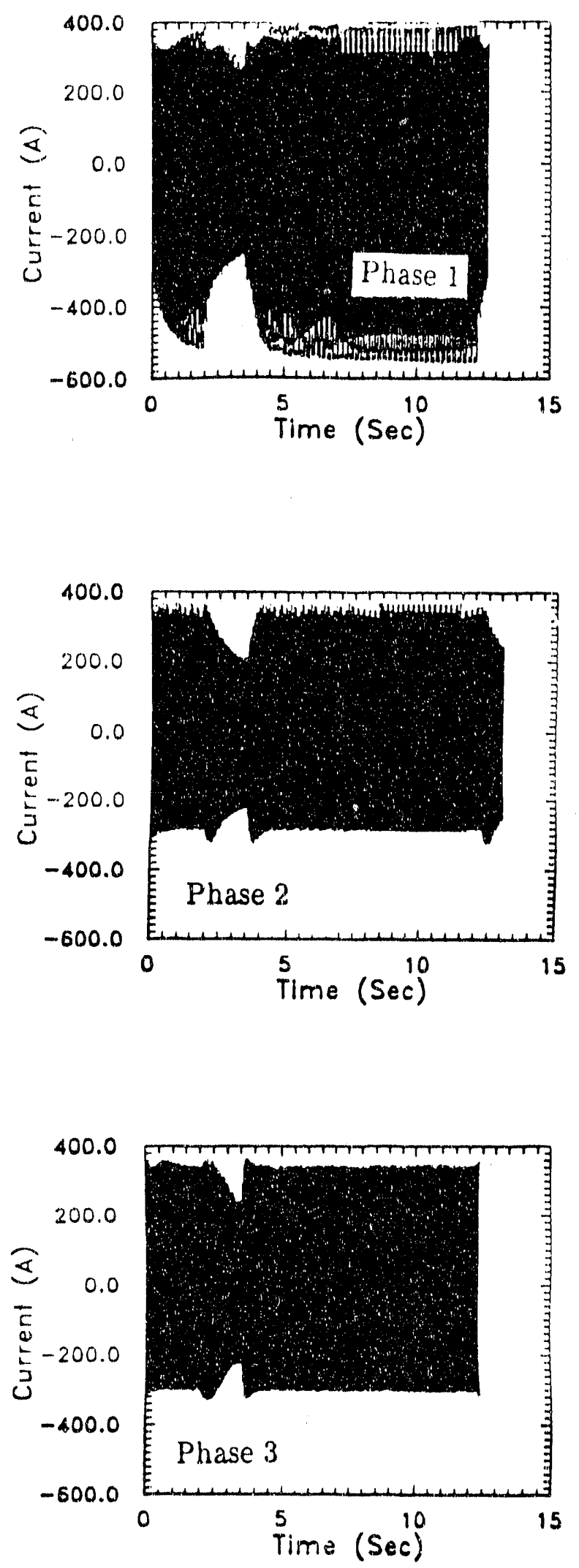

Figure 21. Load Current Envelopes for Configuration 1A with Dc Switched On, Off, and On. 


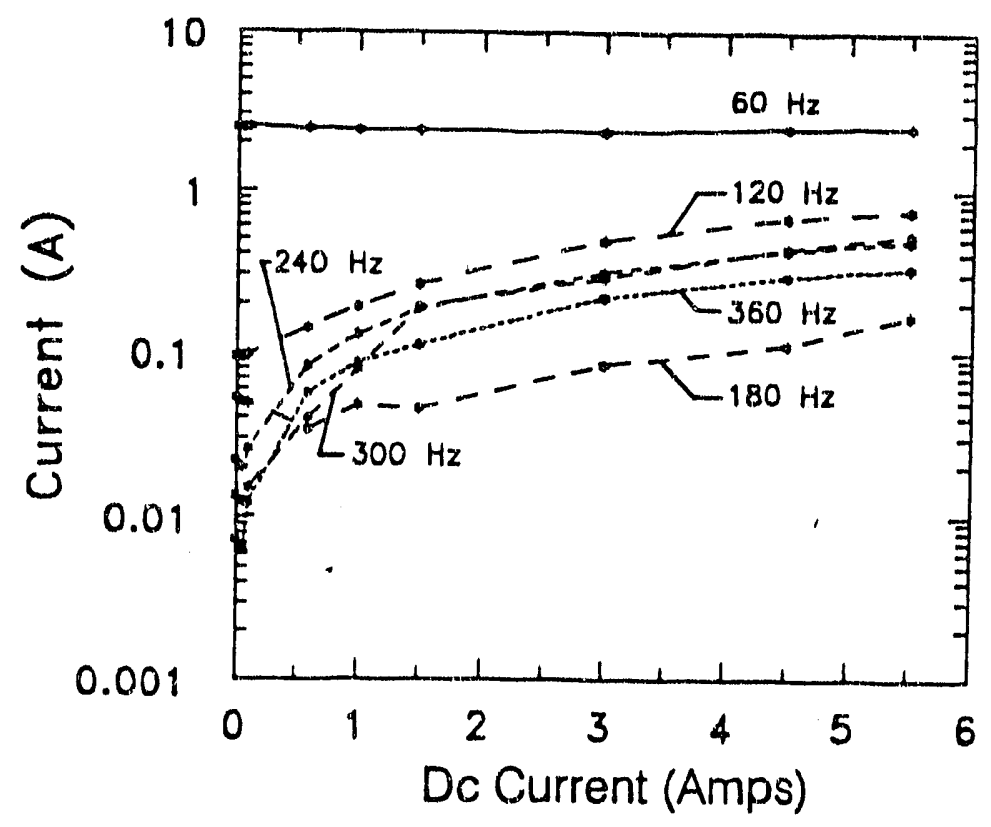

a. Current Spectral Harmonics

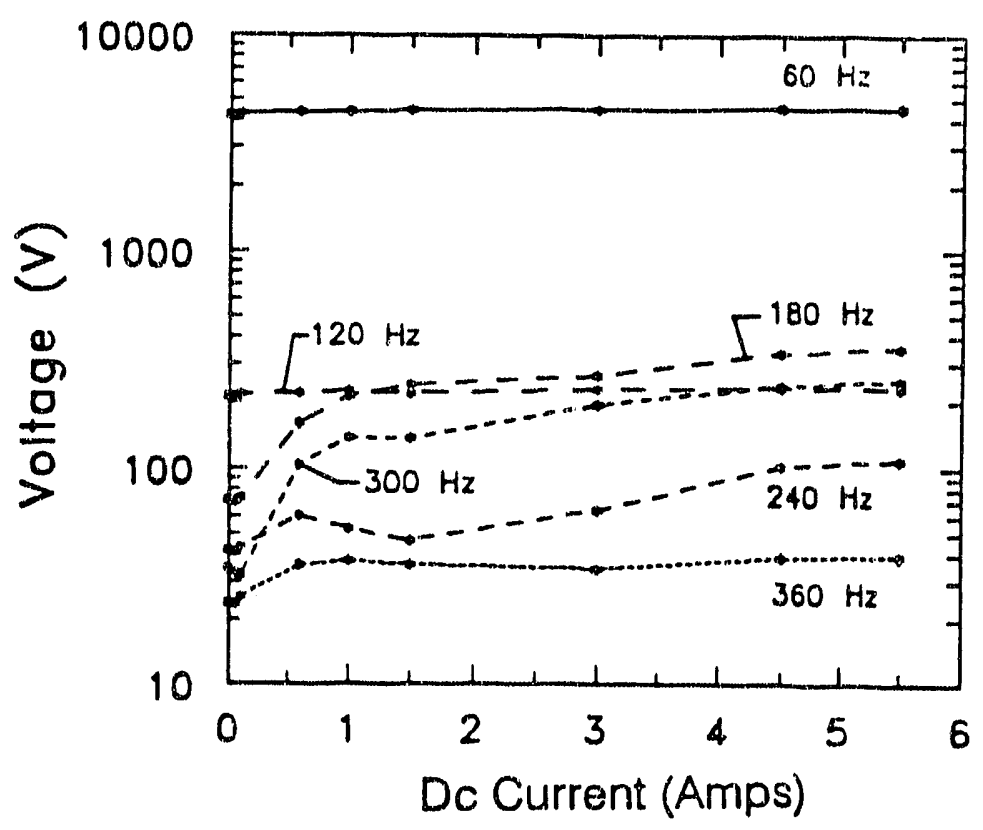

b. Voltage Spectral Harmonics

Figure 22. Harmonic Content vs. Dc Current Level for Phase 1, Configuration 1A. 


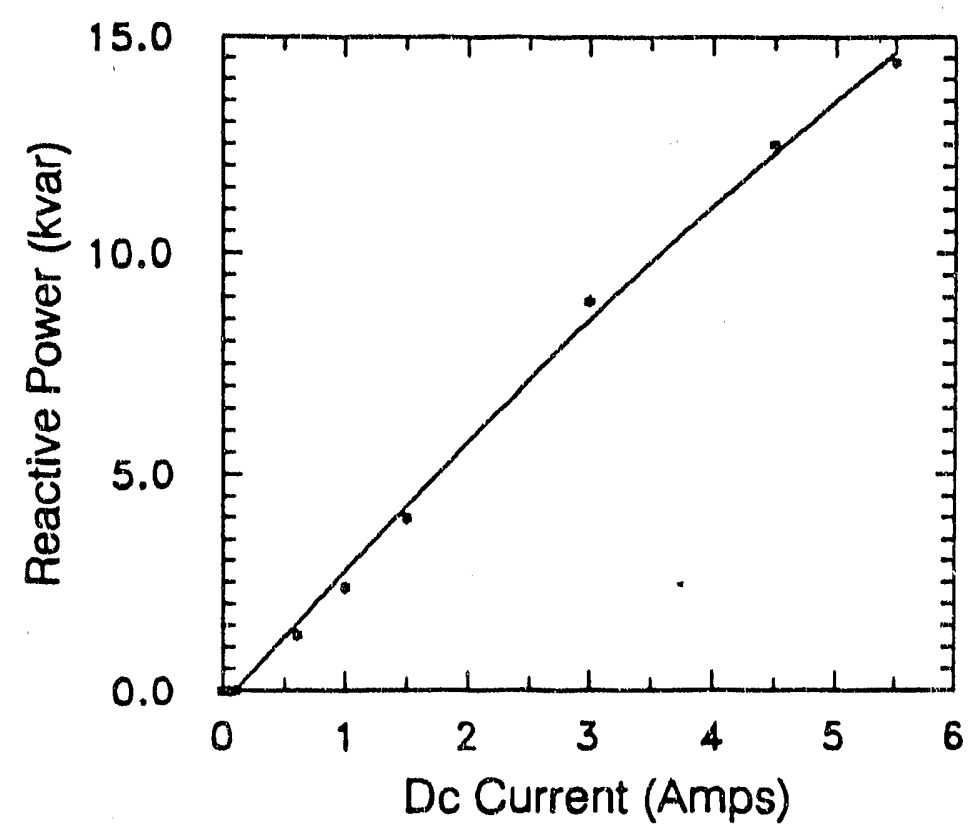

a. High Dc Current Injection

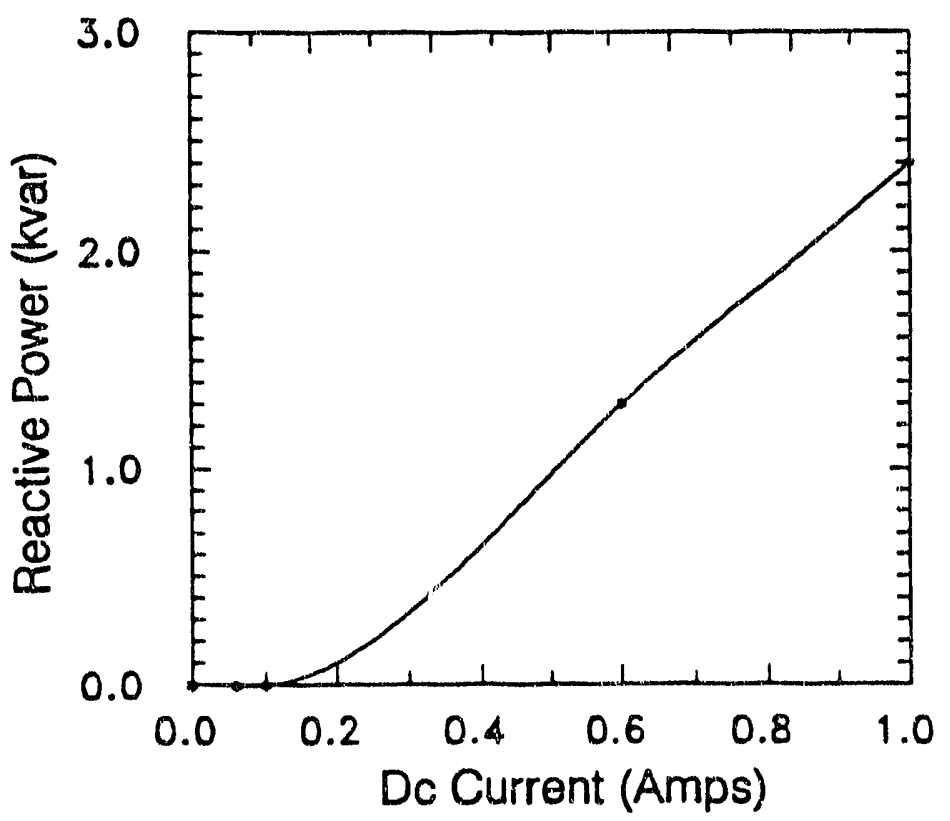

b. Low Dc Current Injection

Figure 23. Reactive Power on Phase 1 vs. Dc Current Injection Level. 
As noted in the envelope plots, there appears to be an $L / R$ time constant associated with the system, and it appears that this quantity is a function of the dc current injection level. This time constant could be determined directly from the envelope plots, or from the transient behavior of the reactive power demand, as the dc injection is switched off. This latter approach was used: it involved finding the time taken for the reactive power to drop to 0.368 of its steady-state value with the dc injection on. This corresponds to a 1/e time constant, a commonly used measure in linear systems. In the present case, with nonlinear core saturation, it is by no means certain that an exponential decay of these responses is indicated. Nevertheless, this provides a convenient way of describing the transient decay of the system.

Figure 24 presents this observed time constant for the $1 \mathrm{~A}$ configuration and illustrates a decreasing system relaxation time as the dc injection increases. This finding is consistent with the idea that the normally large core inductance decreases drastically as the core saturates, thereby decreasing the effective $L / R$ time constant of the system. In the case of no dc injection, there normally will be an in-rush transient which is observed when the transformer is first energized by the ac power. Such transients can last for seconds. No such transient was observed in the data for this configuration with zero dc injection.

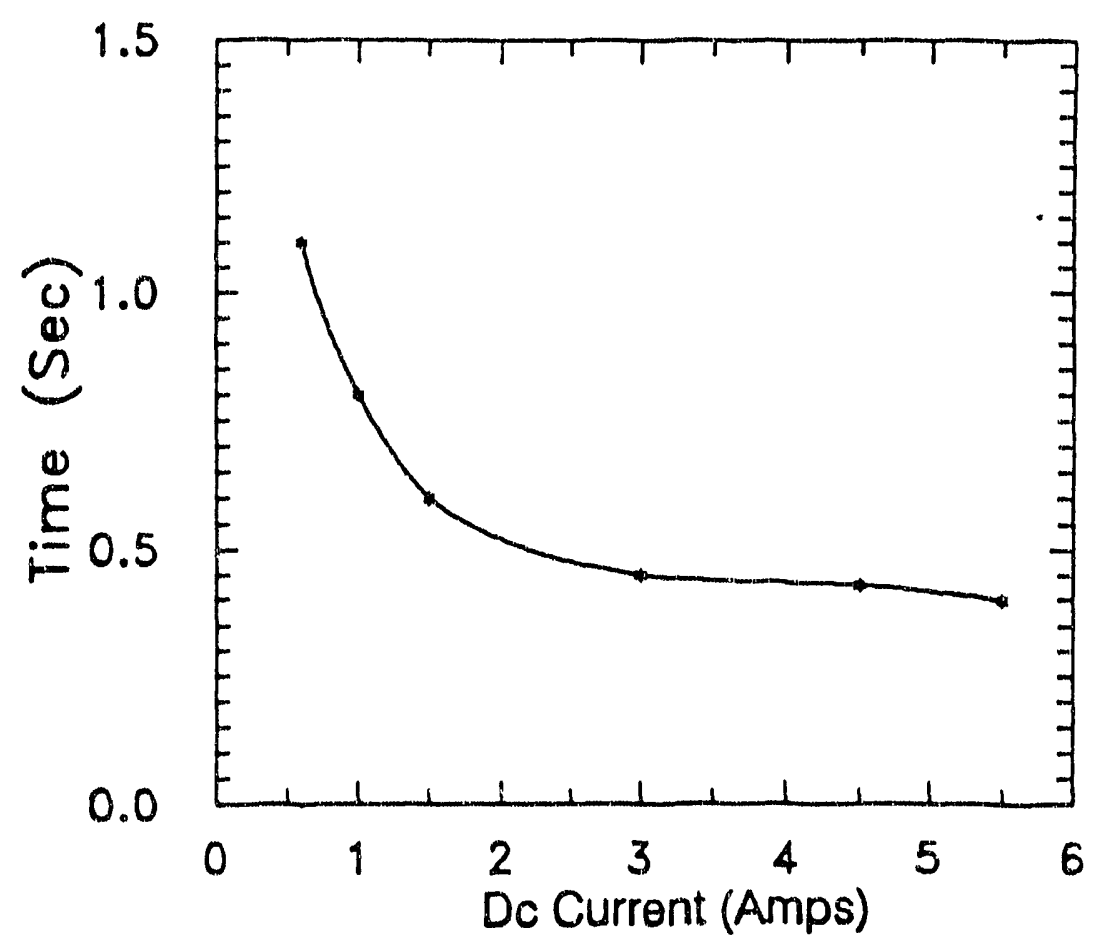

Figure 24. System Relaxation Time vs. Dc Current Injection Level for Configuration 1A. 


\subsection{Configuration 2}

Configuration 2, as shown in Figure 4, consists of a $Y-Y$ transformer at the source end of the $12.47-\mathrm{kV}$ line, with a $\Delta$-grounded-Y transformer at the load end. The dc injection in this case is in the load circuit. For this configuration, the initial in-rush transient with no dc injection is large and its time constant is several tens of seconds. Figure 25 presents the neutral current measured in the load section of the line.

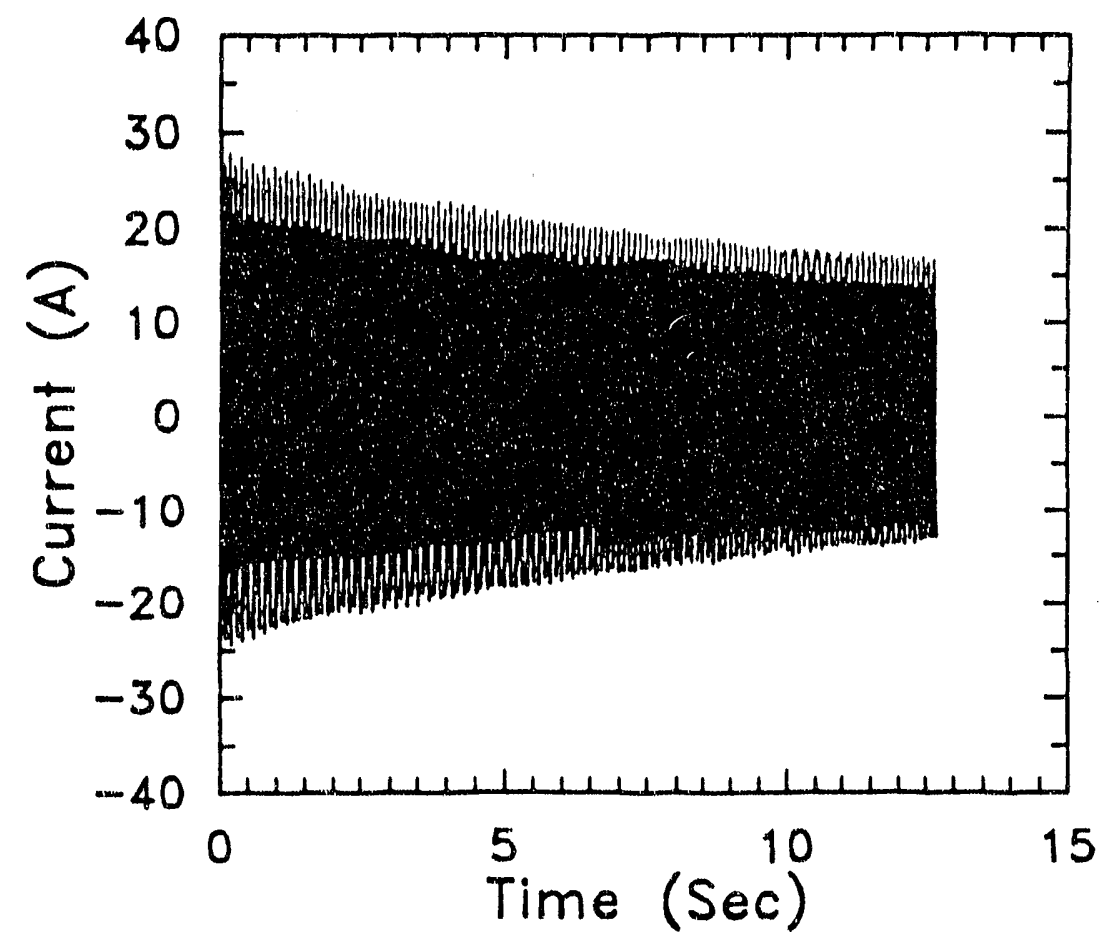

Figure 25. Neutral Current in Transformer Secondary (Load) for Configuration 1B with No Dc Injection.

For this configuration, an attempt was made to determine an effective relaxation time constant. It was observed that even for the smallest dc current injection used $(5.0 \mathrm{~A})$, the system relaxation time was very fast, well under the 0.5 -second time noted for the previous case. Evidently, the lowest current injection had already driven the transformer into saturation. 
The harmonic content of the $12.47-\mathrm{kV}$ phase 1 curr int and voltage is shown in Figures $26 \mathrm{a}$ and $26 \mathrm{~b}$, respectively, as a function of the dc injection level. The fact that the harmonic content of the current jumps by about 1 order of magnitude as the dc current level increases from 0.0 to $5.0 \mathrm{~A}$ indicates that the core saturation occurs somewhere in this range. As in the previous case, the behavior of the phase 1 neutral voltage is not affected as much by the dc injection.

Figure 27 presents the increase in reactive power on phase 1 for configuration 2. Evidently, the dc injection in the load end of the system does not have as much of an effect on changing the reactive power demand as does the dc injection on the high-voltage side of the transformer, as was shown in Figure 23. 


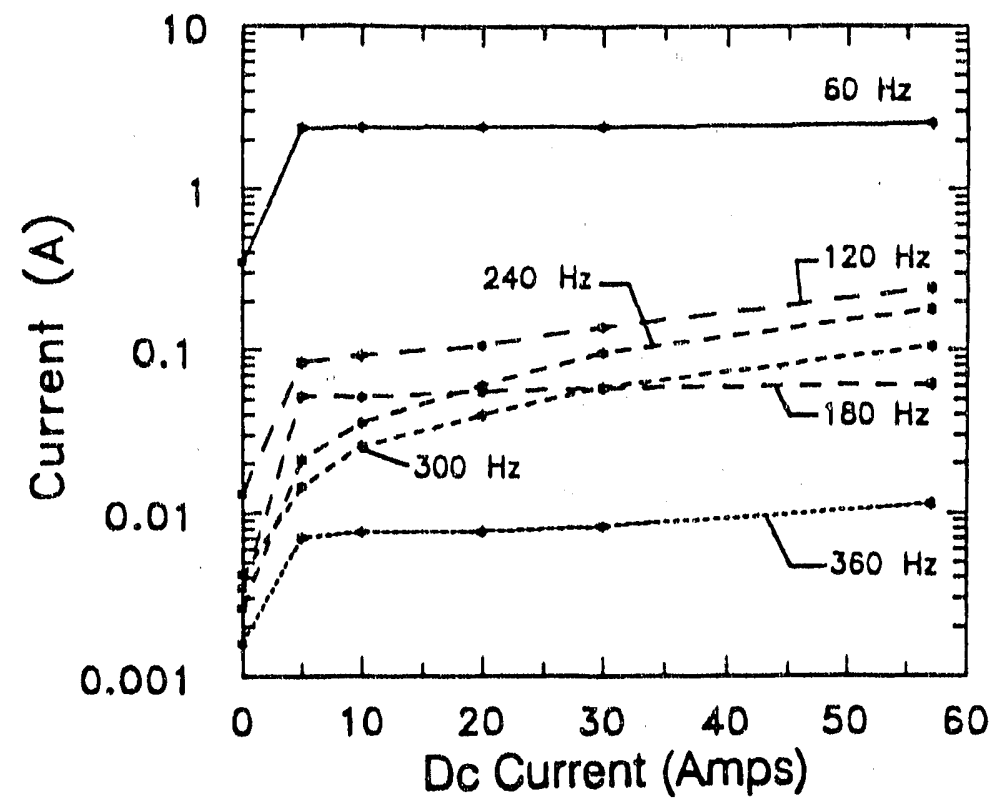

a. Current Spectral Harmonics

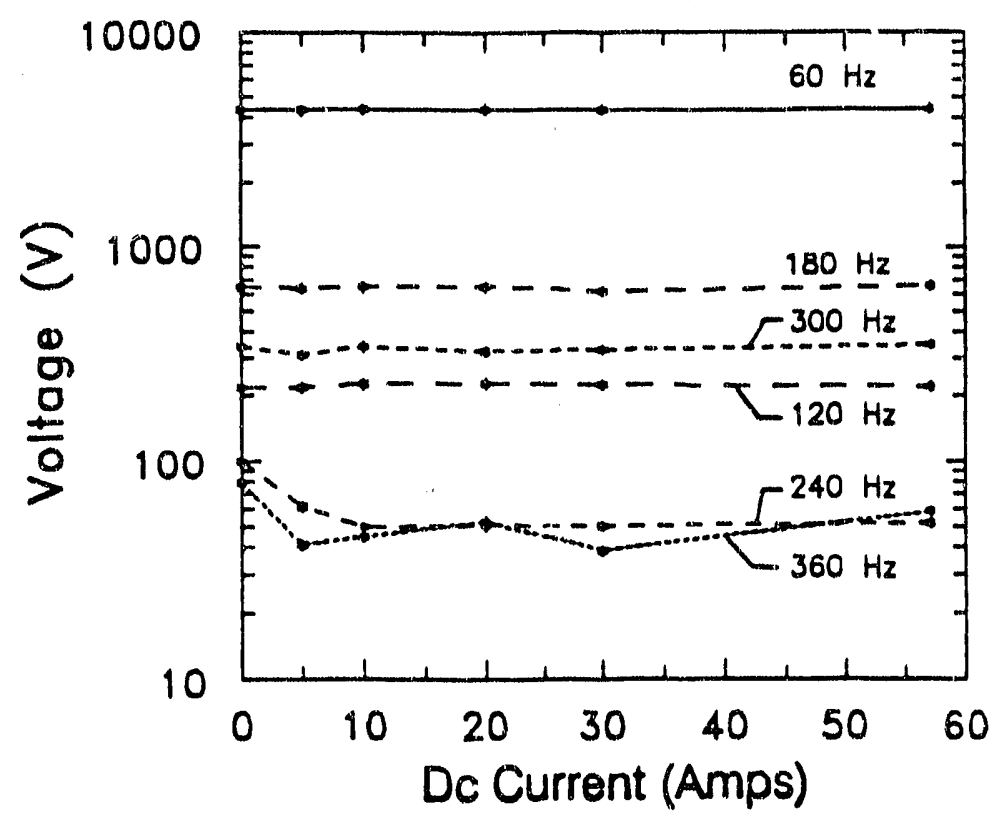

b. Voltage Spectral Harmonics

Figure 26. Harmonic Content vs. Dc Current Level for Phase 1 of Configuration 2. 


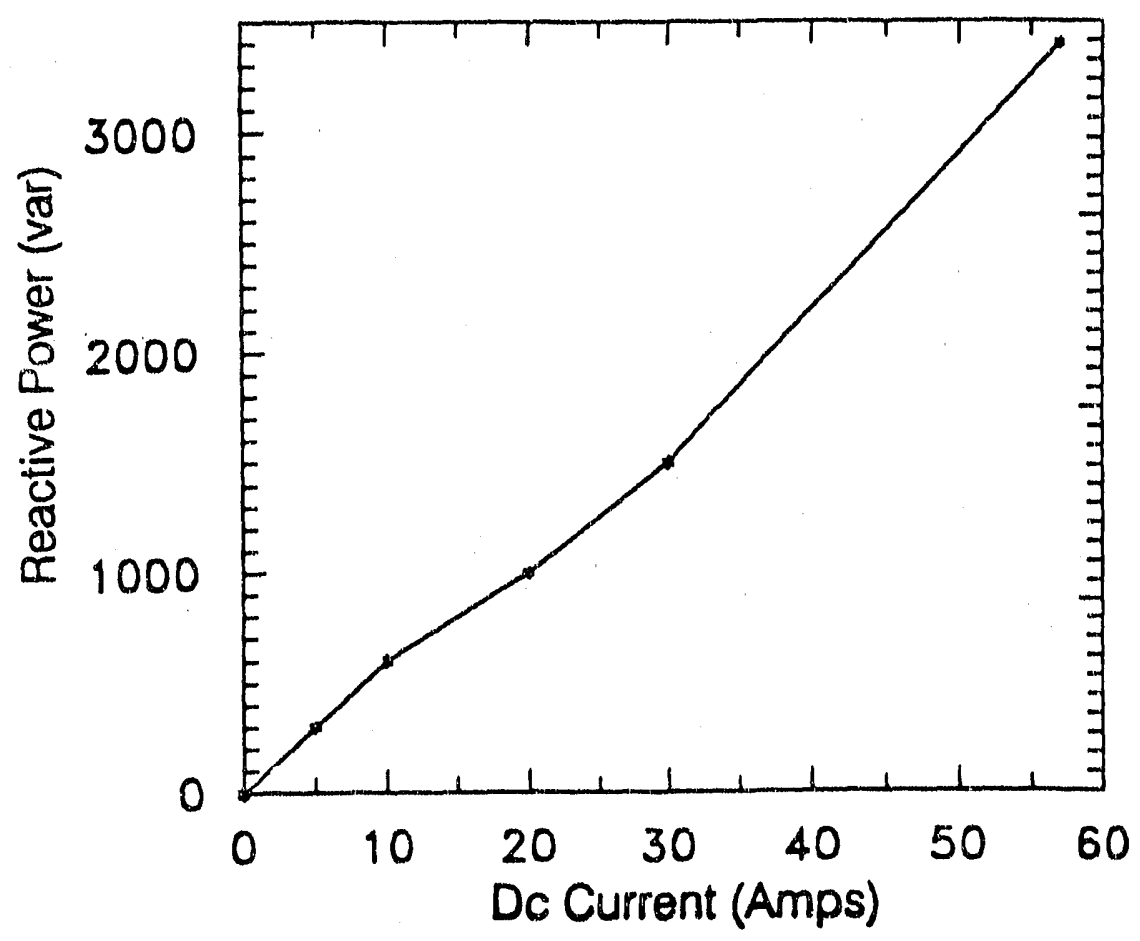

Figure 27. Reactive Power on Phase 1 vs. Dc Current Injection Level. 


\subsection{CONCLUSIONS}

The basic measurements made in this experiment can be used to answer most of the questions posed in Section 1.0 as experimental objectives. Other measurements were also made, providing additional information. Detailed observations of the test results are presented in Section 7.0.

In general, if the dc injection is limited to the primary side of the transformer as in configuration 1A (Figure 2, grounded $\mathrm{Y}-\mathrm{Y}$ ) the majority of the effects are seen in the primary circuit. However, the harmonic distortion at lower-order harmonics (Figures 9b, 13, 14b, and 22) will be passed to the secondary with potentially adverse effects on the connecting load. Also, with sufficient dc injection, the generator supplying the transformers is subjected to a very high reactive power demand (Figure 16).

For cases in which the dc injection is on the secondary side as in configurations $1 B$ and 2 (Figure 3, grounded Y-Y, and Figure 4, $\Delta$-grounded-Y), the harmonic content of the secondary side is quite high, and saturation occurs with a relatively low level of dc injection (Figure 14). However, the reactive power demand on the primary side is significantly lower for these configurations (Figure 27).

Transformer damage is dependent on the dc injection level and direction and on the core's magnetic history and thermal performance. During this experiment, there was no apparent damage to the test transformers from the series of multiple, 10-15 and 26 second tests at various de injection levels. The thermal mass of coolant in the test transformer was so large that several minutes of injection at saturation level would have been required to cause physical damage; hence, there would be no damage expected during a 10-15 second test. It should be remembered, however, that MHD-EMP is expected to have a duration of several hundreds of seconds, and that damage to transformers due to such heating cannot be ruled out.

While the transformer response is certainly nonlinear, the response time of the transformer can be evaluated as if the system were linear. The time constant determined in this way is found to be much lower than that seen in transformer tests at lower dc injection levels on large power transformers. This suggests that response time is strongly dependent on injected current levels and that the effects of higher levels of dc injection for a shorter duration could produce very high reactive power demands and harmonic distortions in a few tenths of a second. 
Finally, the possibility that the added reactive power load would result in the blowing of fuses on the primary circuit appears to be a concern for configuration 1A. For example, Figure 19 clearly indicates that a current imbalance results form the injection of $\mathrm{dc}$ in the neutral of the primary. Assuming a normal full-load current of $3.5 \mathrm{~A}$ per phase, phase 1 with 5.5-A dc injection is found to carry about $5 \mathrm{~A}$ for the duration of the injection. Hence, the possibility that on an actual power system the primary fuses will blow with sufficient $d c$ excitation is very real. In addition the neutral currents are quite large under even low-level $d c$ injection (Figure 20) and could result in a failed neutral conductor or high level harmonic injection into equipment via the neutral, which could cause equipment failure. This is referred to as the "smoking neutral" phenomenon in situations generating high harmonic content in the neutral conductor. 


\subsection{REFERENCES}

1. Albertson, V.D., and J.A. Van Baelen, "Electric and Magnetic Fields at the Earth's Surface due to Auroral Currents," IEEE Trans. PAS, Vol. PAS-89, No. 2, April, 1970.

2. Pirjola, R., "Geomagnetically Induced Currents in the Finnish $400 \mathrm{kV}$ Power Transmission System," Physics of the Earth and Planetary Interiors, Vol. 53, pp. 214-220, Elsevier Science Publishers, 1981.

3. Pirjola, R., "Induction in Power Transmission Lines During Geomagnetic Disturbances," Space Science Reviews, Vol. 35, No. 2, pp. 185-193, 1983.

4. Kappenman, J.G., and V.D. Albertson, "Bracing for the Geomagnetic Storms," IEEE Spectrum, pp. 27-33, March 1990.

5. Legro, J.R., et al., Study to Assess the Effects of High Altitude Electromagnetic Pulse on Electric Power Systems, Phase I Final Report, ORNL/Sub/8343374/1/V2, Oak Ridge National Laboratory, Feb. 1986.

6. Legro, J.R., et al. Study to Assess the Effects of Magnetohydrodynamic Electromagnetic Pulse on Electric Power Systems, Phase I Final Report, ORNL/Sub/83-43374/1/V3, Oak Ridge National Laboratory, May 1985.

7. Tesche, F.M., et al., Magnetohydrodynamic Electromagnetic Pulse (MHDEMP) Interaction with Power Transmission and Distribution Systems, ORNL/Sub/90-SG828/1, Oak Ridge National I.aboratory, February 1992.

8. Smith, R.J., Circuits, Devices And Systems, 2nd ed., John Wiley and Sons, New York, 1971.

9. Callan, Elizabeth, private communication with the author, Mission Research Corp., Albuquerque, NM, June 15, 1990.

10. Papoulis, A., The Fourier Integral And Its Applications, McGraw Hill, New York, 1962. 


\section{INTERNAL DISTRIBUTION}

1-10. P. R. Barnes

11. G. E. Courvilie

12. P. S. Gillis

13. M. A. Kuliasha

14. B. W. McConnell

15. D. T. Rizy

16. R. B. Shelton
17. J. N. Stone

18. J. P. Stovall

19. ORNL Paterit Office

20. Central Research Library

21. Document Reference Section

22-24. Laboratory Records

25. Laboratory Records-RC

\section{EXTERNAL DISTRIBUTION}

\section{ORNL Distribution}

25. V. D. Albertson, Dept. of Electrical Engineering, University Of Minnesota, 123 Church Street, S.W., Minneapolis, MN 55455.

27. G. Applegren, Main Coordination Center, 1n301 Swift Road, P.O. Box 278, Lombard, Illinois 60148.

28. G. H. Baker, HQ DNA/RAEE, 6801 Telegraph Road, Alexandria, VA 22310-3398.

29. G. D. Birney, Western Area Power Administration, P. O. Box 3402, Golden, CO 80401.

30. P. D. Blair, Energy and Materials Program, Congress of the United States, Office of Technology Assessment, Washington, DC 20510.

31. Ellery Block, SAIC, 6725 Odyssey, Huntsville, AL 35806-3301.

32. L. Bolduc, Hydro Quebec, 1800 Montee Ste Julie, Varennes, QC, Canada, J3X 1S1.

33. E. H. Brehm, Dipl..Ing., ASEA Brown Boveri AG, Postfach 351, Abt. GK/NP 25, 6800 Mannheim 1, Germany.

34. Larry Bressler, Western Area Power Administration, P. O. Box 3402, Golden, CO 80401.

35. B. G. Buchanan, Computer Science Department, University of Pittsburgh, 206 Mineral Industries Building, Pittsburgh, PA 15260. 
36. W. J. Budney, Distribution Systems, Public Service Electric \& Gas Co., 20 Park Plaza, Newark, NJ 07101.

37. H. S. Cabayan, Lawrence Livermore National Laboratory, P.O. Box 5504, L-81, Livermore, CA 94550.

38. R. F. Campbell, Transmission \& Electrical Projects, Tennessee Valley Authority, 3N 53A Missionary Ridge Place, Chattanooga, TN 37402-2801.

39. J. Chadwick, 902 Glamis Circle, Signal Mountain, TN 37377.

40. D. J. Christofersen, Manager, Electrical Engineering Division, United Power Association, P. O. Box 800, Elk River, MN 55330-0800.

41. P. Chrzanowski, Evaluation \& Planning Program, Lawrence Livermore National Lab, P.O. Box 808, L-81, Livermore, CA 94550.

42. R. F. Chu, Research Engineer, Philadelphia Electric Co., Research Division (S10-1), 2301 Market Street, Philadelphia, PA 19101.

43. Lynn Coles, Principal Policy Advisor, SERI, 1617 Cole Boulevard, Golden, CO 80401.

44. O. R. Compton, Richmond Plaza, P. O. Box 26666, Richmond, Virginia 23261.

45. T. B. Cook, 80 Castiewood Dr., Pleasanton, CA 94566.

46. G. H. Copion, U.S. Department Of Energy, Rm. 8F089, 1000 Independence Avenue, S.W., Washington, DC 20585.

47. C. Cuttica, PJM - Valley Forge Corporate CTr., 955 Jefferson Avenue, Norristown, PA 19403.

48. G. Dahlen, Royal Institute of Technology, Tds, P.O. Box 70043, S-10044, Stockholm, Sweden.

49. S. J. Dale, Manager Transmission Technology Institute, ABB Power T\&D Company Inc., Centennial Campus, 1021 Main Campus Drive, Raleigh, NC.

50. Raymond Dunlop, Director of Research, New England Power Service Co., 25 Research Drive, Westborough, MA 01582.

51. H. Elbadaly, Underground T\&D Research Manager, Consolidated Edison Company, 4 Irving Place, New York, NY 10003.

52. D. Fagnan, Philadelphia Electric Co., 2301 Market Street, Philadelphia, PA 19101. 
53. W. E. Ferro, Electric Research and Management, Inc., P.O. Box 165, State College, PA 16804.

54. Larry Fry, Teledyne Brown Engineering, MS-50, 300 Sparkman Dr., Huntsville, AL 35807-7007.

55. R. Gates, EMP Prrgram Manager, FEMA, RM 606, 500 C Street, S.W., Washington, DC 20472.

56. P. R. Gattens, Allegheny Power, 800 Cabin Hill Dr., Greensburg, PA 15601.

57. M. R. Gent, President, North American Electric Reliability Council, 101 College Road East, Princeton, New Jersey 08540-8060.

58. M. Granger, Hydro-Quebec, Planning Systems Division, 855 East Ste-Catherine, 20 ieme etage, Montreal, Quebec, Canada, H2L 4PS.

59. J. D. Gregory, Southern Company Services, Inc., P. O. Box 2625, Birmingham, AL $35202-2625$

60. I. Gyuk, Program Manager, U.S. Department of Energy, 1000 Independence Ave., S.W., Washington, DC 20585.

61. Wayne Hilson, Manager, Transmission and Electrical Systems Department, Tennessee Valley Authority, Missionary Ridge, 3 North 41, 1101 Market Street, Chattanooga, TN 37402-2801.

62. Allan Hirsch, Vice President (Environmental Sciencies) and Director (Washington Operations), Midwest Research Institute, 5109 Leesburgh Pike, Suite 414, Falls Church, VA 22041.

63. Helen M. Ingram, Director, Udall Center for Studies in Public Policy, The University of Arizonia, 803/811 East First Street, Tucson, AZ 85719.

64. J. Kappenman, Minnesota Power, 30 W. Superior St., Duluth, Minnesota 55802.

65. S. Kashyap, Defense Research Establishment - Ottawa, Electronics Division, 3701 Carling Ave., Ottawa, Ontario K1A0ZA, Canada.

66. J. L. Koepfinger, Director, Systems Studies and Research, Duquesne Light Company, One Oxford Center, 301 Grant Street (19-5), Pittsburgh, PA 15279.

67. B. Korbutiak, Alberta Power, Lid., 10035 195th St., Edmondton, Alberta T5J 2V6, Canada.

68. J. Kulsetas, Division Manager/Research Director, Norwegian Electric Power Research Institute, Division of High Voltage Technology, N-7034 Trondheim, Norway. 
69. E. Larsen, General Electric, ESDS Bldg. 2, Rm 642, One River Road, Schenectady, NY 12345.

70. Major Robert Launstein, Defense Nuclear Agency, DNA/RAEE, 6801 Telegraph Rd., Alexandria, VA 22310.

71. R. C. Liimatainen, Committee on Science, Space and Technology, 374 Rayburn House Office Bidg., Rm. B., Washington, DC 20515.

72. J. Lloyd, CEHND-ED-SY, U.S. Army, Engineering Division Huntsville, P.O. Box 1600, Huntsville, AL 35807.

73. C. L. Longmire, Mission Research Corporation, P.O. Drawer 719, Santa Barbara, CA 93102.

74. Calvin D. MacCracken, President, Calmac Manufacturing Corp., 101 West Sheffield Avenue, Englewood, NJ 07631.

75. David Mayhall, Lawrence Livermore National Laboratory, P.O. Box 808, L-156, Livermore, CA 94550.

76. A. P. Meliopoulos, Georgia Tech, School of Electrical Engineering, Atlanta, GA 30332 .

77. S. R. Mendoza, Salt River Project, P.O. Box 52025, Phoenix, AZ 85072-2025.

78. N. V. Mesland, Tot Keuring Van Elektrotechnische, Materialen, 6800 ET Arnhem, P.O. Box 9035, The Netherlands.

79. D. L. Nickel, Manager, ABB Power Systems, Inc., 777 Penn Center Blvd., Pittsburgh, PA 15235-5927.

80. S. Nilsson, Program Manager, Electric Power Research Institute, Electrical Systems Division, 3412. Hillview Avenue, P.O. Box 10412, Palo Alto, CA 94303.

81. B. M. Pasternack, American Electric Power Service Corp., 1 Riverside Plaza, P.O. Box 16631, Columbus, OH 43216-6631.

82. J. Z. Ponder, PJM Interconnection, 955 Jefferson Ave., Norristown, PA $19420^{\circ}$

83. J. W. Porter, Electric Power Research Institute, Suite 100, 1019 Nineteenth St. N.W., Washington, DC 20036.

84. M. Rabinowitz, Electric Power Research Institute, 3412 Hillview Avenue, F.O. Box 10412, Palo Alto, CA 94303.

85. J. J. Ray, Division of Syst. Planning, BPA, P.O. Box 3621, Portland, OR 97208. 
86. T. W. Reddoch, Electrotek Concepts, Inc., 10305 Dutchtown Rd., Suite 103, Knoxville, TN 37932.

87. J. R. Rempel, Physicist, Defense Intelligence Agency, Washington, DC 20340-6761.

88. Dietrich J. Roesler, U.S. Department of Energy, CE-141, 1000 Independence Avenue SW, Washington, DC 20585.

89. F. Rosa, Division of System Intg., Nuclear Regulatory Commission, MS P1030, Washington, DC 20555.

90. J. E. Scalf, Florida Power \& Light Company, P. O. Box 14000, 700 Universe Blvd., Juno Beach, FL 33408.

91. W. J. Scott, Hq DNA/RAEE, 6801 Telegraph Road, Alexandria, VA 22310-3398.

92. Joe Sefcik, Nuclear Design, Lawrence Livermore National Lab, P.O. Box 808, L-22, Livermore, CA 94550.

93. C. H. Shih, Manager, Electrical Research, American Electric Power Service Corp., 1 Riverside Plaza, Columbus, OH 43215.

94. Jacqueline B. Shrago, Director, Office of 'Technology Transfer, Vanderbilt University, 405 Kirkland Hall, Nashville, TN 37240.

95. M. L. Sloan, Austin Research Associate, 1101 Capital of Texas Highway S., Building B, Suite 210, Austin, TX 78746.

96. P. Sullivan, Philadelphia Electric Co., 2301 Market Street (S10-1), Philadelphia, PA 19101.

97. E. R. Taylor, ABB Power Systems, Inc. , 777 Penn Center Blvd., Pittsburgh, PA 15235-5927.

98. R. L. Taylor, Director - Power Supply, Florida Power \& Light Co., 9250 W. Flagler, Miami, FL 33102.

99. F. M. Tesche, Consulting Scientist, 6921 Spanky Branch Dr., Dallas, TX 75248.

100. M. V. Thaden, Potomac Electric Power Co., 1900 Pennsylvania Ave., NW, Rm. 311, Washington, DC 20068.

101. J. Towle, 3906 Bagley Ave. N., Suite 100, Seattle, WA 98103.

102. E. F. Vance, 6885 HWY 1187, Fort Worth, TX 76140. 
103. D. R. Volzka, Senior Project Engineer, Wisconsin Electric Power Company, 333 West Everett Street, Milwaukee, WI 53201.

104. C. L. Wagner, 4933 Simmons Dì., Export, PA 15632.

105. R. Walling, General Electric Company, Building 2, Rm 507, One River Road, Schenectady, NY 12345.

106. R. C. Webb, Defense Nuclear Agency, RAEE, 6801 Telegraph Road, Alexandria, VA 22310.

107. E. P. Wigner, Consultant, 8 Ober Road, Princeton, NJ 08540.

108. M. W. Wik, Forsvarets Materielverk, Stockholm, S-11588, Sweden.

109. Martin Williams, Professor, Department of Economics, Northern Illinois University, DeKalb, IL 60115.

110. D. Woodford, Suite 400, 1619 Pembina Ave., Winnipeg, Manitoba, R-3T-2G5, Canada.

111. F. S. Young, Director, Electrical Systems Division, Electric Power Research Institute, P.O. Box 10412, Palo Alto, CA 94303.

112. R. W. Zwickl, Space Environment Laboratory, Mail Stop R/E/SE, Boulder, CO 80303.

113. Office of Assistant Manager for Energy, Research and Development, DOE-ORO, P.O. Box 2001.

114-123. OSTI, U.S. Department of Energy, P.O. Box 62, Oak Ridge, TN 37831.

\section{DNA Distribution}

124. Air Force Space Command, Headquarters, DEES/D C DE MIO, Peterson AFB, CO 80914-5001.

125. Atomic Energy, The Pentagon, Assistant to the Secretary of Defense, Executive Assistant, Washington, DC 20301-3050.

126. BDM International Inc., Library, P.O. Box 9274, Albuquerque International, Albuquerque, NM 87119.

127. BDM International Inc., E. Dorchak, 7915 Jones Branch Drive, McLean, VA 22102. 3396.

128. Booz-Allen \& Hamilton, Inc., Technical Library, 4330 East West Highway, Bethesda, MD 20814-4455. 
ORNL/SUb/89-SE912/1

129. Central Intelligence Agency, OSWR/STD/MTB, Washington, DC 20505.

130. Central Intelligence Agency, OSWR/NED, Washington, DC 20505.

131. Defense Communications Engineer Center, Code R410, 1860 Wiehle Avenue, Reston, VA 22090-5285.

132. Defense Intelligence Agency, Director, RTS-2B, Washington, DC 20340.

133. Defense Intelligence Agency, Director, VP-TPO, Washington, DC 20340.

134. Defense Nuclear Agency, RAEV, 6801 Telegraph Road, Alexandria, VA 22310.

135-144. Defense Nuclear Agency, RAEE, 6801 Telegraph Road, Alexandria, VA 22310.

145-146. Defense Nuclear Agency, TITL, 6801 Telegraph Road, Alexandria, VA 22310.

147. Defense Nuclear Agency, RAAE, 6801 Telegraph Road, Alexandria, VA 22310.

148. Defense Research Establishment Ottawa, S. Kashyap, Ottawa, Ontario, Canada K1A0Z4.

149. Defense Technical Information Center, DTIC/FDAB, Cameron Station, Alexandria, VA 22304-6145.

150. Department of the Navy, Command \& Control Programs, OP 941, Washington, DC 20350.

151. Department of Commerce, NOAA/MASC Security Office, MC43, G. Reeve, 325 Broadway, Boulder, CO 80303.

152. Department of Commerce, NOAA/MASC Security Office, MC43, W. Utlaut, 325 Broadway, Boulder, CO 80303.

153. Department of Commerce, NOAA/MASC Security Office, MC43, D. Peach, 325 Broadway, Boulder, $\mathrm{CO} 80303$.

154. Department of the Air Force, Air Force CTR For Studies \& Analysis, AFCSA/SAMI (R. Griffin), Washington, DC 20330-5420.

155. E-Systems, Inc., ECI Division, Mail Stop 3, Tech Info CTR, P.O. Box 12248, St. Petersburg, FL 33733.

156. EG\&G Special Projects Inc., J. Giles, Albuquerque Operations, 2450 Alamo Avenue, SE, AJbuquerque, NM 87106. 
157. Electro-Magnetic Applications, Inc., D. Merewether, P.O. Box 8482, Albuquerque, NM 87198-8482.

158. General Research Corp., W. Naumann, P.O. Box 6770, Santa Barbara, CA 931606770 .

159. Harry Diamond Laboratories, Director, SLCHD-NW-TN (G MERKEL), 2800 Powder Mill Road, Adelphi, MD 20783-1197.

160. Harry Diamond Laboratories, Director, SLCHD-NW-EP (21100), 2800 Powder Mill Road, Adelphi, MD 20783-1197.

161. Harry Diamond Laboratories, Director, W. Patterson, 2800 Powder Mill Road, Adelphi, MD 20783-1197.

162. Harry Diamond Laboratories, Director, SLCIS-IM-TL (81100), 2800 Powder Mill Road, Adelphi, MD 20783-1197.

163. IIT Research Institute, I. Mindel, 10 W. 35th Street, Chicago, IL 60616-3703.

164. Institute for Defense Analyses, Tech Info Services, 1801 N. Beauregard Street, Alexandria, VA 22311-1772.

165. Jaycor, R. Poll, P.O. Box 1577, Santa Monica, CA 90406-1577.

166. Jaycor, E. Wenaas, P.O. Box 85154, San Diego, CA 92186-5154.

167. Jaycor, M. Schultz, Jr., 1608 Spring Hill Road, Vienna, VA 22182-2270.

168. Joint Strategic Target Planning Staff, The Joint Staff, JLWT (Threat Analysis), Offutt AFB, NE 68113-50001.

169. Joint Strategic Target Planning Staff, The Joint Staff, JKC (DNA REP), Offutt AFB, NE 68113-50001.

170. Kaman Sciences Corporation, DASIAC, Santa Barbara Operations, P.O. Box 1479, Santa Barbara, CA 93102-1479.

171. Kaman Sciences Corp., Library/B. Kinslow, P.O. Box 7463, Colorado Springs, CO 80933-7.43.

172. Kaman Sciences Corp., Washington Operations Division, DASIAC, 2560 Huntington Ave., Suite 200, Alexandria, VA 22303.

173. Kamana Sciences Corporation, Technical Library, Dikewood Division, 6400 Uptown Blvd., N.E. Suite 300E, Albuquerque, NM 87110. 
174. Metatech Corporation, W. Radasky, P.O. Box 1450, Goleta, CA 93116-1450.

175. Mission Research Corp., J. Lubell, 4935 North 30th Street, Colorado Springs, CO 80919-4199.

176. Mission Research Corp., A. Chodorow, 1720 Randolph Rd., SE, Albuquerque, NM 87106-4245.

177. Mission Research Corp., Tech Info Center, P.O. Drawer 719, Santa Barbara, CA 93102-0719.

178. National Security Agency, Director, R-54, Fort George G Meade, MD 20755-6000.

179. Naval Research Laboratory, Commanding Officer, Code 2627 (TECH LIB), Washington, DC 20375-5000.

180. Office of the Sec of Defense, Director, Document Control, Net Assessment, Room 3A930, The Pentagon, Washington, DC 20301.

181. Office Secretrary Defense, U S Nuclear Command \& Central Sys Support Staff, SAB H Sequine, Pentagon, Room 3E 172, Washington, DC 20301-3040.

182. Pacific-Sierra Research Corp., H. Brode, 12340 Santa Monica Blvd, Los Angeles, CA 90025-2587.

183. R \& D Associates, Document Control, P.O. Box 92500, Los Angeles, CA 90009.

184. R \& D Associates, J P Castillo, P.O. Box 9377, Albuquerque, NM 87119-9377.

185. Rockwell International Corp., G. Smith, P.O. Box 3105, Anaheim, CA 92803-3105.

186. S-Cubed, J. Knighten, A Division of Maxwell Laabs, Inc., P.O. Box 1620, La Jolla, CA 92038-1620.

187. Science \& Engrg Associates, Inc., Robert L. Charters, P.O. Box 3348, Seattle, WA 98009-3348.

188. Science Applications Intl. Corp., P.J. Dowling, 2860 S Circle Dr., St. 2400, Colorado Springs, CO 80906.

189. Science Applications Intl. Corp., W. Chadsey, P.O. Box 1303, McLean, VA $22102-$ 1303.

190. Space \& Naval Warfare Systems CMD, Commander, Technical Library, Department of the Navy, Washington, DC 20363-0001.

191. SRI International, J. Prewitt, 333 Ravenswood Ave., Menlo Park, CA S44U25-3434. 
192. Strategic Air Command/XRFS, Headquarter, XRFS, Department of the Air Force, Offutt AFB, NE 68113-5001.

193. The Joint Staff, J-3/Nuc. Operations Br., Strat. Operations Br., Washington, DC 20318 .

194. The Joint Staff, C3S (ER) Analysis Div, Washington, DC 20318.

195. The Joint Staff, J-6F D Butts, Washington, DC 20318.

196. TRW Inc., DH4/2461, G.E. Morgan, TRW Space \& Defense, One Space Park, Redondo Beach, CA 90278-1071.

197. U S Army Engineer Div Huntsville, Division Engineer, CEHND-SY J LOYD, P.O. Box 1600, West Station, Huntsville, AL 35807-4301.

198. U S Army Strategic Defense Command, CSSD-SL, P.O. Box 1500, Huntsville, AL 35807.

199. U S Army Nuclear \& Chemical Agency, Commander, MONA-NU (D. Bash), 7500 Backlick Rd., Bldg. 2073, Springfield, VA 22150-3198.

200. Under Secretary of Defense, Director, Strat \& Theater NUC Forces, The Pentagon, RM 3E 129, Strat \& Theater NUC Forces (O\&SS), Washington, DC 20301-3090.

201. USA Survivability Management Office, Director, SLCSM-SE J BRAND, 2800 Powder Mill Road, Adelphi, MD 20783-1145.

202. USAF/LEEEU, HQ, LEEE, Washington, DC 20330.

203. Weapons Laboratory, NTN, Kirtland AFB, NM 87117-6008.

204. Weapons Laboratory, WL/SUL, Kirtland AFB, NM 87117-6008. 

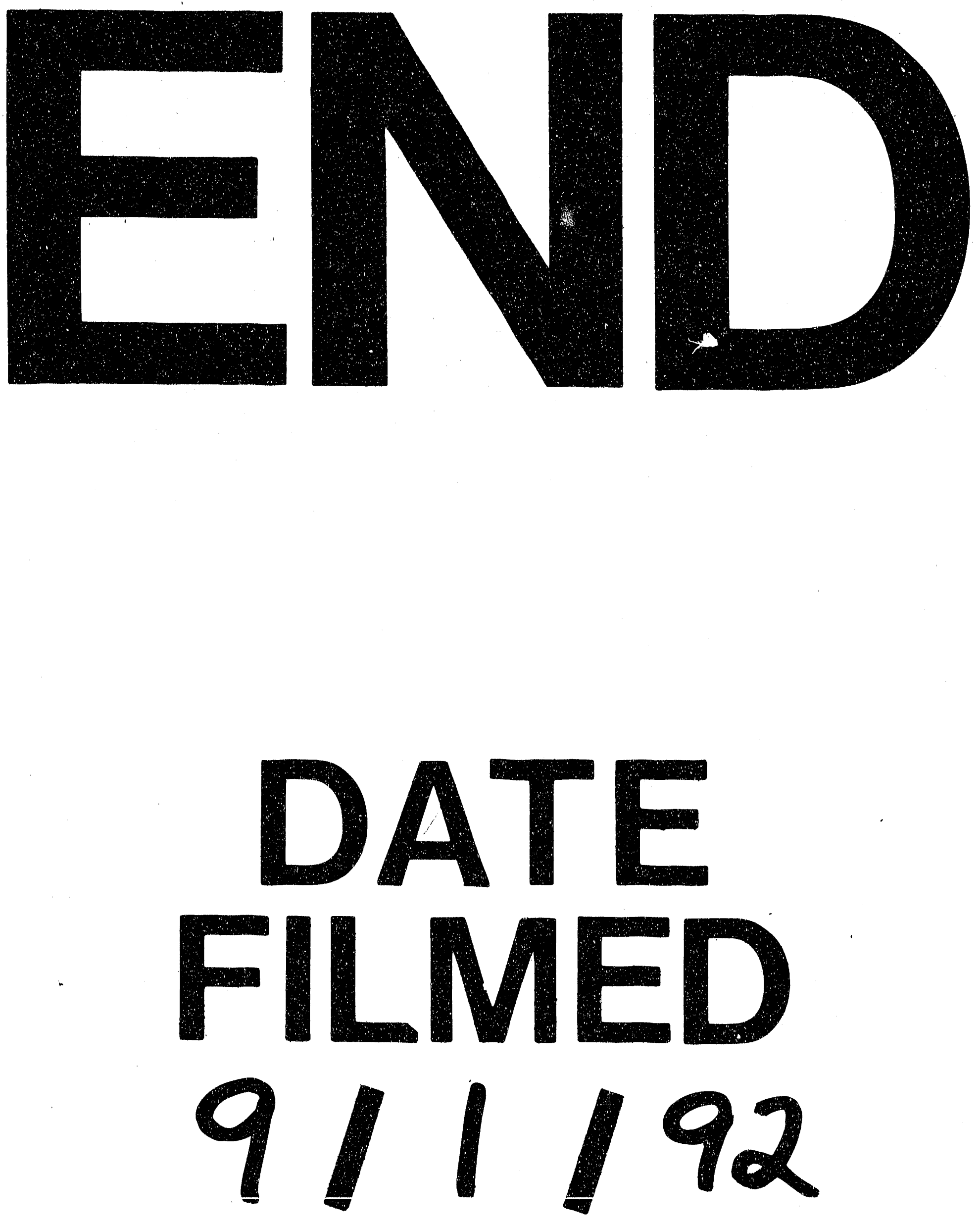
